\title{
Objective impairments of gait and balance in adults living with HIV-1 infection: a systematic review and meta-analysis of observational studies
}

\author{
Karina Berner ${ }^{1 *}$ (D) Linzette Morris ${ }^{1}$, Jochen Baumeister ${ }^{2}$ and Quinette Louw ${ }^{1}$
}

\begin{abstract}
Background: Gait and balance deficits are reported in adults with HIV infection and are associated with reduced quality of life. Current research suggests an increased fall-incidence in this population, with fall rates among middleaged adults with HIV approximating that in seronegative elderly populations. Gait and postural balance rely on a complex interaction of the motor system, sensory control, and cognitive function. However, due to disease progression and complications related to ongoing inflammation, these systems may be compromised in people with HIV. Consequently, locomotor impairments may result that can contribute to higher-than-expected fall rates. The aim of this review was to synthesize the evidence regarding objective gait and balance impairments in adults with HIV, and to emphasize those which could contribute to increased fall risk.

Methods: This review followed the Preferred Reporting Items for Systematic Reviews and Meta-Analyses (PRISMA) guidelines. An electronic search of published observational studies was conducted in March 2016. Methodological quality was assessed using the NIH Quality Assessment Tool for Observational Cohort and Cross-Sectional Studies. Narrative synthesis of gait and balance outcomes was performed, and meta-analyses where possible.

Results: Seventeen studies were included, with fair to low methodological quality. All studies used clinical tests for gait-assessment. Gait outcomes assessed were speed, initiation-time and cadence. No studies assessed kinetics or kinematics. Balance was assessed using both instrumented and clinical tests. Outcomes were mainly related to center of pressure, postural reflex latencies, and timed clinical tests. There is some agreement that adults with HIV walk slower and have increased center of pressure excursions and -long loop postural reflex latencies, particularly under challenging conditions.

Conclusions: Gait and balance impairments exist in people with HIV, resembling fall-associated parameters in the elderly. Impairments are more pronounced during challenging conditions, might be associated with disease severity, are not influenced by antiretroviral therapy, and might not be associated with peripheral neuropathy. Results should be interpreted cautiously due to overall poor methodological quality and heterogeneity. Locomotor impairments in adults with HIV are currently insufficiently quantified. Future research involving more methodological uniformity is warranted to better understand such impairments and to inform clinical decision-making, including fall-prevention strategies, in this population.
\end{abstract}

Keywords: HIV-1 infection, Gait, Postural balance, Falls

\footnotetext{
*Correspondence: kberner@sun.ac.za

'Division of Physiotherapy/Central Analytical Facilities (CAF) 3D Human

Biomechanics Unit, Department of Rehabilitation \& Health Sciences, Faculty

of Medicine and Health Sciences, Stellenbosch University, PO Box 241, Cape

Town 8000, South Africa

Full list of author information is available at the end of the article
} 


\section{Background}

In Southern Africa, about $18.9 \%$ of adults aged 1549 years are HIV-1-seropositive [1]. Both globally and in Sub-Saharan Africa, life-expectancy in people living with HIV (PLHIV) is now comparable to that of seronegative adults [2-4]. HIV/AIDS has evolved into a chronic condition due to the success of highly-active antiretroviral therapy (HAART) [2], but this is paralleled by increasing morbidity. In 1990, HIV/AIDS was the 33rd most important cause of disability-adjusted life years (DALYs) globally, but has since increased to fifth position [5]. In Sub-Saharan Africa, a high prevalence of HIV-associated disability, including impairments in mobility and motor function, is reported in PLHIV [6].

Gait and balance deficits have been reported in PLHIV despite controlled viral load [7-10] and are associated with reduced quality of life (QOL) [11, 12]. Current HAART regimes have less neurotoxic effects than older versions, and thus there is a lower risk of developing peripheral neuropathy [13]. However, the prevalence of peripheral neuropathy remains quite high among PLHIV (between 30\% and 62\%), and the prevalence of locomotor impairments remains a concern [14-17]. PLHIV have an increased incidence of falls [18-20], and fall rates among middle-aged PLHIV are comparable to that of seronegative older adults, aged 65 years and older [18]. These falls are attributed to balance impairments [20].

HIV-1 infection may compromise motor function at multiple levels of the nervous system [13]. Structural MRIstudies have shown that PLHIV present with white matter alterations, including reduced pontocerebellar tract integrity, leading to gait and postural instability [21]. It remains unclear whether gait and balance impairments noted in PLHIV are due to the disease process or its treatment [22]. One hypothesis is that these deficits occur as a complication of ongoing inflammation [14, 23, 24]. PLHIV, although adherent to treatment, experience non-AIDS defining complications resembling geriatric processes at an earlier than expected age $[23,25]$. Chronic immune activation may be an underlying mechanism [23]. This accelerated aging manifests in middle-aged PLHIV as the accumulation of various co-morbidities, including frailty $[23,26]$.

Of further concern is that PLHIV are four times more at risk of fractures due to accelerated bone demineralization [27] and sarcopenia [28], and the proposed interplay between these conditions [29]. Low bone mineral density and sarcopenia are associated with balance problems and falls $[28,30]$. These complications may be intrinsic to HIV infection (e.g. due to metabolic changes) or HAARTinduced [31]. It has been suggested that the loss in bone mineral density is a result of increased bone turnover, especially during the first 12 to 24 months after HAARTinitiation [32-34]. Various protease inhibitor (PI) or nucleoside reverse transcriptase inhibitor (NRTI) type antiretroviral therapies (ART) show a correlation with mitochondrial toxicity [22], damaging the structure and function of muscles. In addition, reduced central activation of muscles has also been reported in PLHIV, likely due to impaired oxygen utilisation [35].

Information is building that PLHIV demonstrate gait and balance impairments. However, owing to the variety of observational data, it is difficult to quantify the extent of impairment and to gain insight into which parameters are truly affected and clinically relevant. In elderly populations, several gait and balance parameters have been identified as independent predictors of fall risk, including spatiotemporal, kinetic, kinematic and clinical [36-39]. To the authors' knowledge, no previous systematic review has yet investigated objective impairments of gait and balance in PLHIV. The aim of this review is therefore to synthesize the evidence of objective impairments of gait and balance associated with HIV-1 infection, and to emphasize those which could contribute to increased fall risk. We also aimed to describe the evidence in relation to disease severity, treatment effects, task difficulty, and peripheral neuropathy.

\section{Methods}

This systematic review was conducted according to the Preferred Reporting Items for Systematic Reviews and Meta-Analyses (PRISMA) guidelines [40].

\section{Criteria for considering studies for this review}

Cohort, case-control and cross-sectional studies published in English as peer-reviewed journal articles were considered. Studies were included if they aimed to assess instrumented or non-instrumented objective parameters of gait and/or balance in adults (18-65 years of age) with HIV-1 infection, irrespective of gender. Given the expectation that there would be a paucity of information, studies with and without comparison groups were considered. Quantitative gait outcomes included, but were not limited to, kinematics, kinetics, spatiotemporal measures or clinical tests. Quantitative balance outcomes included, but were not limited to, biomechanical parameters such as center of pressure (COP) measures, and temporal measures via clinical tests. Studies were excluded if participants' age exceeded 65 years, as the prevalence of locomotor impairments is known to increase in older age even in healthy populations [41]. Studies aiming to assess HIV-Associated Neurocognitive Disorder using a neuropsychological test battery were also excluded, regardless of the use of a gross motor component, in an attempt to focus on studies with the primary aim of objectively assessing and describing gait or balance in PLHIV.

\section{Search methods for identification of studies Information sources}

Six computerized bibliographic databases were searched, namely PubMed, Science Direct, EBSCOhost (CINAHL, 
MEDLINE, Africa-Wide Information), Scopus, ProQuest Medical Library and Google Scholar. Following a preliminary search of PubMed, a comprehensive search strategy, including all relevant key word/terms and medical subject headings $(\mathrm{MeSH})$ was developed and adapted for use in subsequent searching of the remaining databases. Search terms included: (HIV-1 OR HIV Infection*) AND (motor function $O R$ biomechanical phenomena $O R$ gait $O R$ postural balance OR locomotor function). The search was restricted to papers published from inception of the database to March 2016. Reference lists of all identified documents were hand-searched to identify additional relevant evidence. In the event of missing data, an attempt was made to contact the authors.

\section{Study selection}

Titles and abstracts of all initial hits were screened by one reviewer (KB). When necessary, consultation with a second reviewer (QL) was pursued. All potential full texts were subsequently screened by these two reviewers, and eligibility criteria were applied independently. Any discrepancies regarding eligibility were discussed between reviewers to reach consensus.

\section{Data collection and analysis Methodological quality appraisal}

One reviewer $(\mathrm{KB})$ appraised the methodological quality of each included study using the National Institutes of Health (NIH) Quality Assessment Tool for Observational Cohort and Cross-Sectional Studies [42]. The tool is designed to aid appraisal of internal validity (potential risk of selection-, information-, or measurement bias, or confounding) of cross-sectional and cohort studies and was therefore appropriate for this review. It comprizes 14 criteria. All criteria can be answered as "yes", "no", "cannot determine", "not applicable" or "not reported". All responses other than "yes" indicate risk of bias. Inherent to the design, cross-sectional studies automatically score "not applicable" on criteria 6, 7,10 and 13. After all 17 articles were scored by the first reviewer, two of these were randomly selected for audit and independently scored by a second reviewer (LM). The scores assigned by each reviewer were compared by specifically discussing those criteria with discrepant scores. Consistent discrepancies were noted specifically for criteria 6,10 and 13 for both studies - which were resolved after agreeing that these criteria should be scored as "not applicable" as per the instrument's instructions. Resultant total scores were similar; thus it was not deemed necessary for the second reviewer to score the remaining 15 articles as well. Each criterion was weighted equally in the overall grading, and studies were not excluded based on quality score, due to the expected dearth of information.

\section{Data extraction}

Data extracted from each study were summarized using a customized Excel spreadsheet, based on Cochrane forms. Information about sample demographics as well as the study aims, study design, known confounders to gait and balance, descriptors of HIV-disease, gait or balance analysis tool or test used, specific objective gait or balance outcomes, dose-response evidence, treatment effects, association of disease severity, association of peripheral neuropathy, findings and limitations of each study were extracted. Principle summary measures were means and standard deviations (SD).

\section{Data analysis or synthesis}

Narrative description of data was done using text summaries or tables as appropriate. For outcomes that were reported in at least two studies, a meta-analysis was conducted in Revman version 5.2, provided that homogeneity in the outcomes and samples existed regarding units of measurement, test conditions, gender and disease severity. Mean differences and $95 \%$ confidence intervals (CI) were calculated via a random effects model, provided that means and SD were reported, and were presented graphically as forest plots. Symptomatic (presenting with various symptoms of chronic HIV disease) and asymptomatic (asymptomatic HIV infection/clinically latent phase of HIV) subgroups of PLHIV were analyzed.

\section{Results}

\section{Study selection}

The initial search in March 2016 produced 799 total hits (Fig. 1). After removing duplicates and applying eligibility criteria, 93 potential titles remained. Thirty studies were subsequently excluded upon reading the abstracts. The main reasons for exclusion were that the outcome measures were not relevant to the review question, participants were not within the specified age range, and study design was inappropriate. Following full text review, the number of studies for inclusion was reduced to 17 . Primary reasons for exclusion were inability to obtain full text, ineligible participants, no raw data and outcomes that were not relevant to the review question.

\section{Study characteristics Critical appraisal of study quality}

Table 1 presents the methodological quality appraisal scores of the included studies, which ranged from fair to poor. A mean score of $40.34 \%$ was obtained, ranging from 7.14\% (lowest internal validity amongst the included studies) to $57.14 \%$ (strongest internal validity amongst the included studies). 


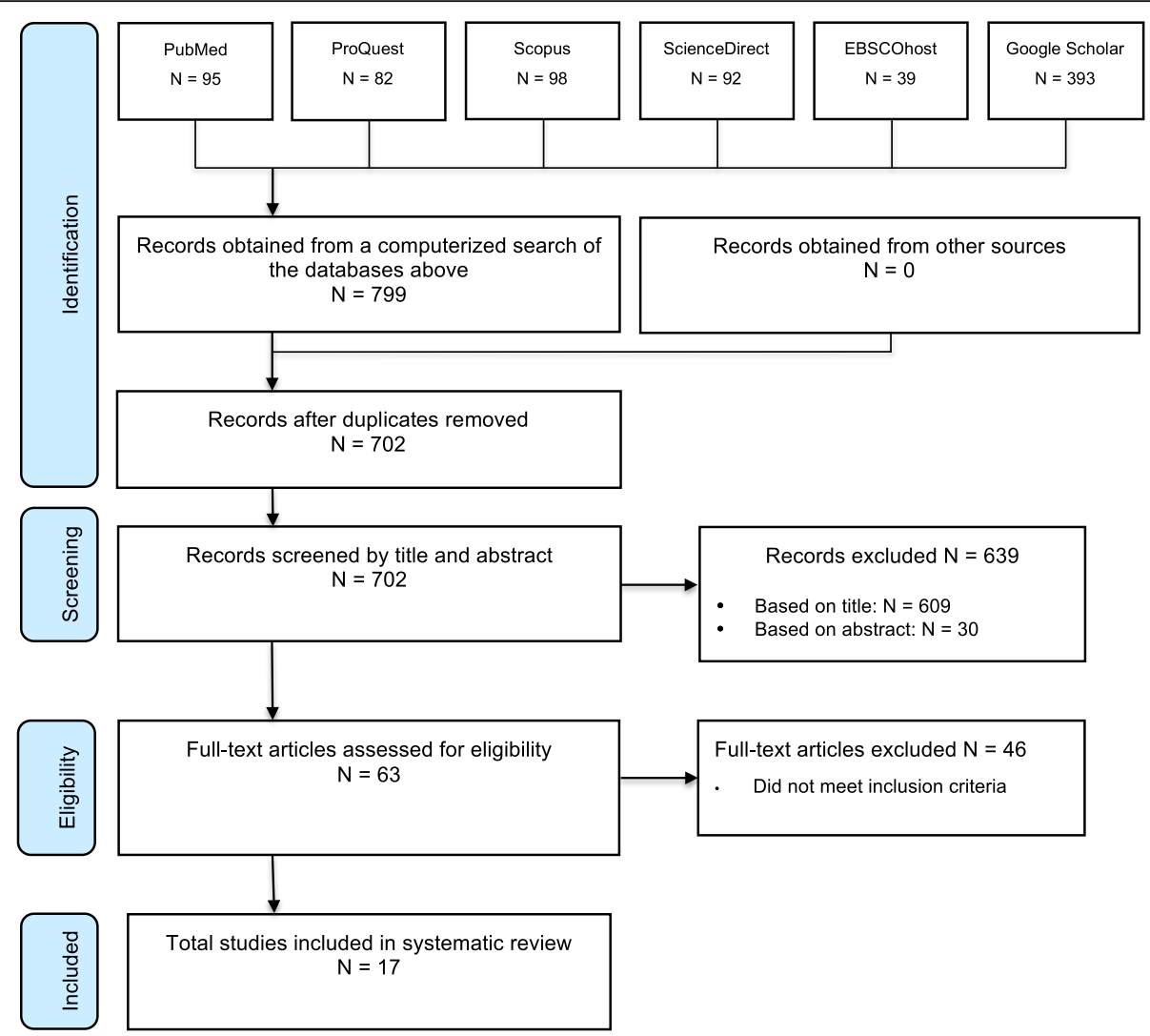

Fig. 1 PRISMA flow diagram of literature search and selection process

\section{Study sample description}

Participant numbers varied from 19 to 447. Six studies did not include a control group [8-10, 12, 18, 35]. Mean ages ranged from 28 to 54.7 years. Two studies included males only [35, 43]. Only one study [44] was conducted in Sub-Saharan Africa. Table 2 summarizes the sample characteristics of all participants, while HIV-specific sample characteristics are presented in Table 3.

\section{Study design, aims and outcomes}

Sixteen studies were cross-sectional, and one was a prospective cohort [9]. Study aims varied (Table 4), but all included objective measurement of balance and/or gait as part of the primary aim. Balance was assessed using both clinical and instrumented tests. All studies used timed clinical tests for assessing gait. No studies assessed gait kinetics or kinematics. Outcomes varied substantially. Table 5 (balance) and Table 6 (gait) present the outcomes assessed per study. Summaries of the results for individual outcomes are presented briefly in Table 7 (balance) and Table 8 (gait), and presented in more detail as additional files (see Additional file 1 for balance and Additional file 2 for gait).

Static balance Five studies assessed static balance using clinical tests. One study [45] assessed Romberg eyes- closed-on-foam and found the frequency of impairment to be higher in PLHIV. Tandem stance time was normal in PLHIV [21]. Four studies assessed single leg stance time $[8,9,21,22]$. Impairments were noted either only with eyes closed, or with synergistic obesity, or when standing on the non-preferred leg (eyes open and closed).

One study [46] assessed COP sway path using a force plate, and found the incidence of increased values to be larger in advanced stages of infection and task difficulty. Sway velocity was examined by another study [47]. A significant increase was found in neurologically symptomatic PLHIV regardless of visual condition, and about $25 \%$ of PLHIV with asymptomatic HIV infection also demonstrated increased values.

Average velocity in anterior-posterior (AP) and average velocity in lateral (LAT) directions were assessed by one study [48]. PLHIV with asymptomatic HIV infection had significantly increased AP only in the eyes closed condition, while PLHIV with symptoms of chronic HIV disease had significantly increased AP both with eyes open and eyes closed, as well as significantly increased LAT (only with eyes closed).

Two studies $[47,48]$ assessed the coefficient of the preferential direction of movement (AP/LAT ratio) and found this to be normal in PLHIV. Romberg ratio of area (RA) 
Berner et al. BMC Musculoskeletal Disorders (2017) 18:325

Page 5 of 26

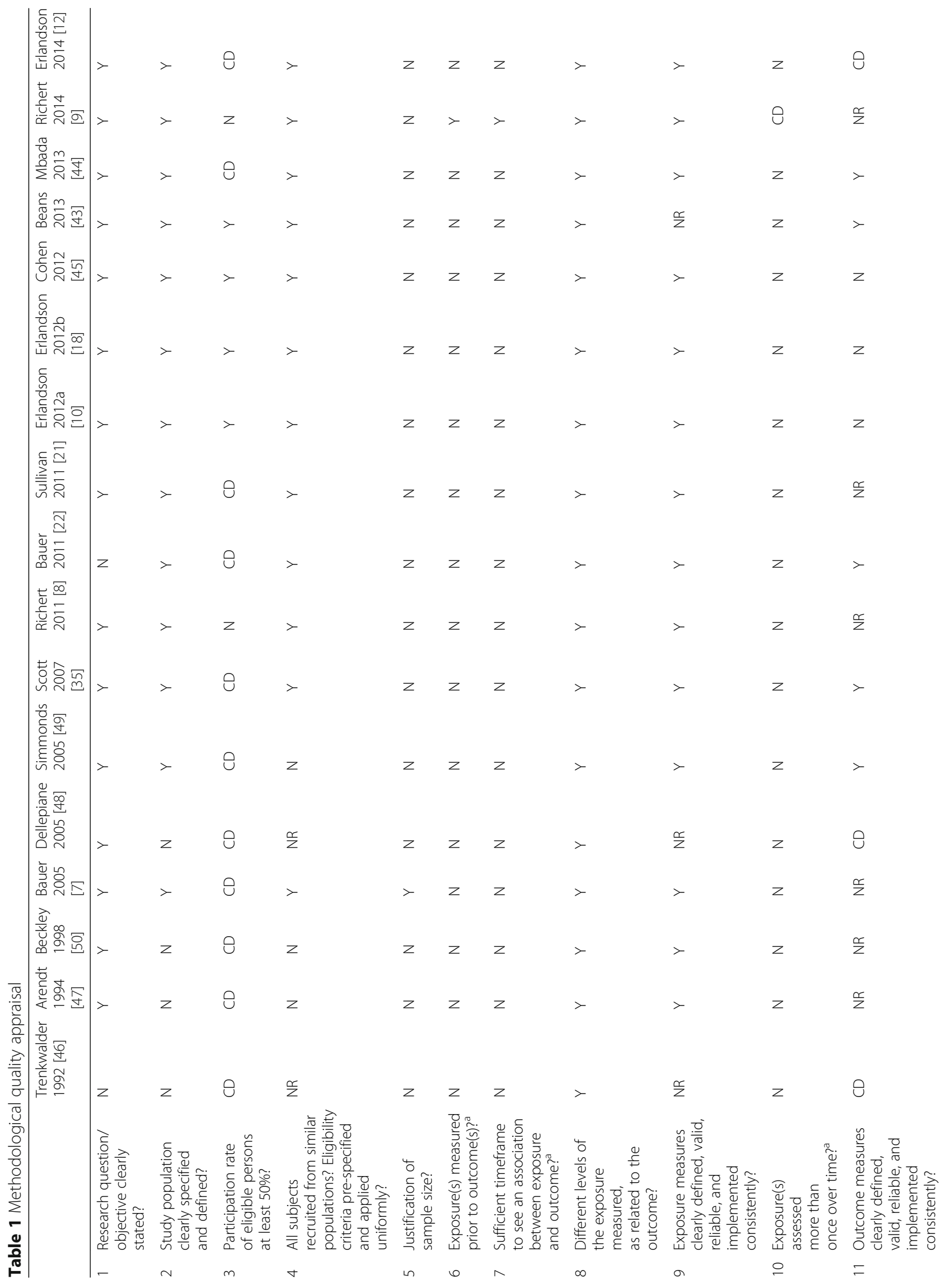




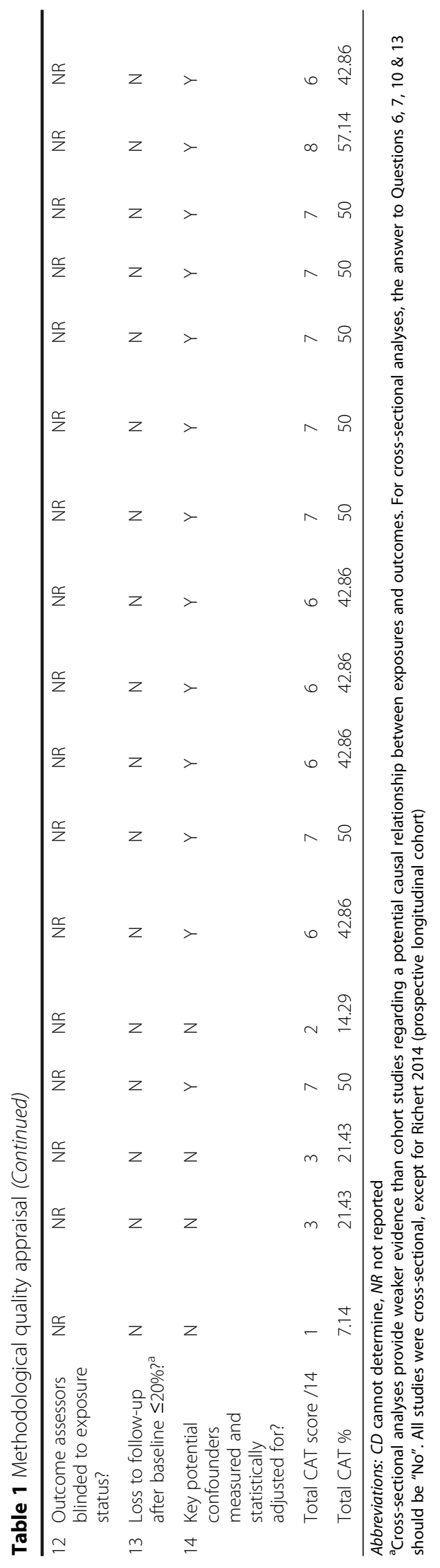




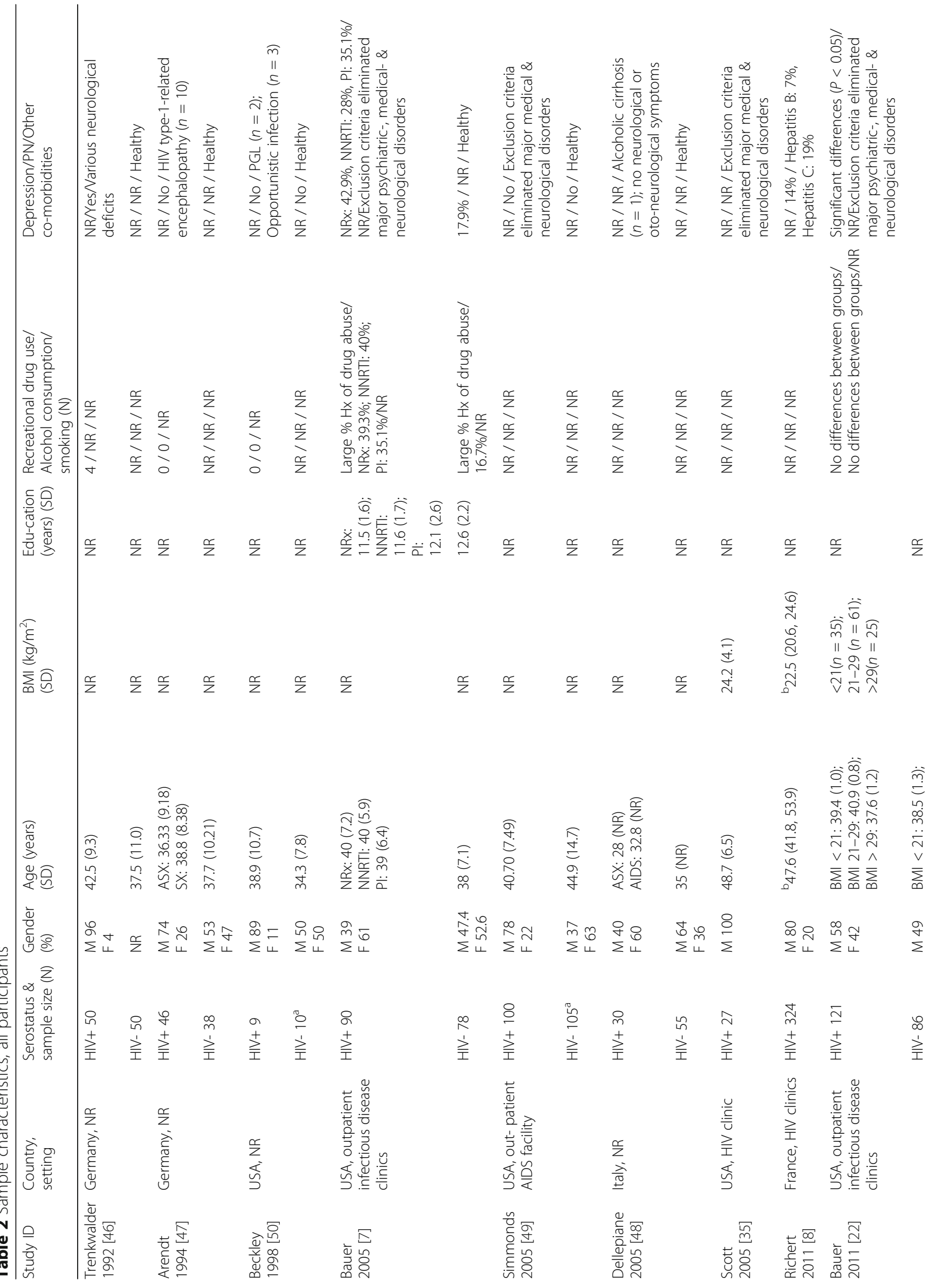




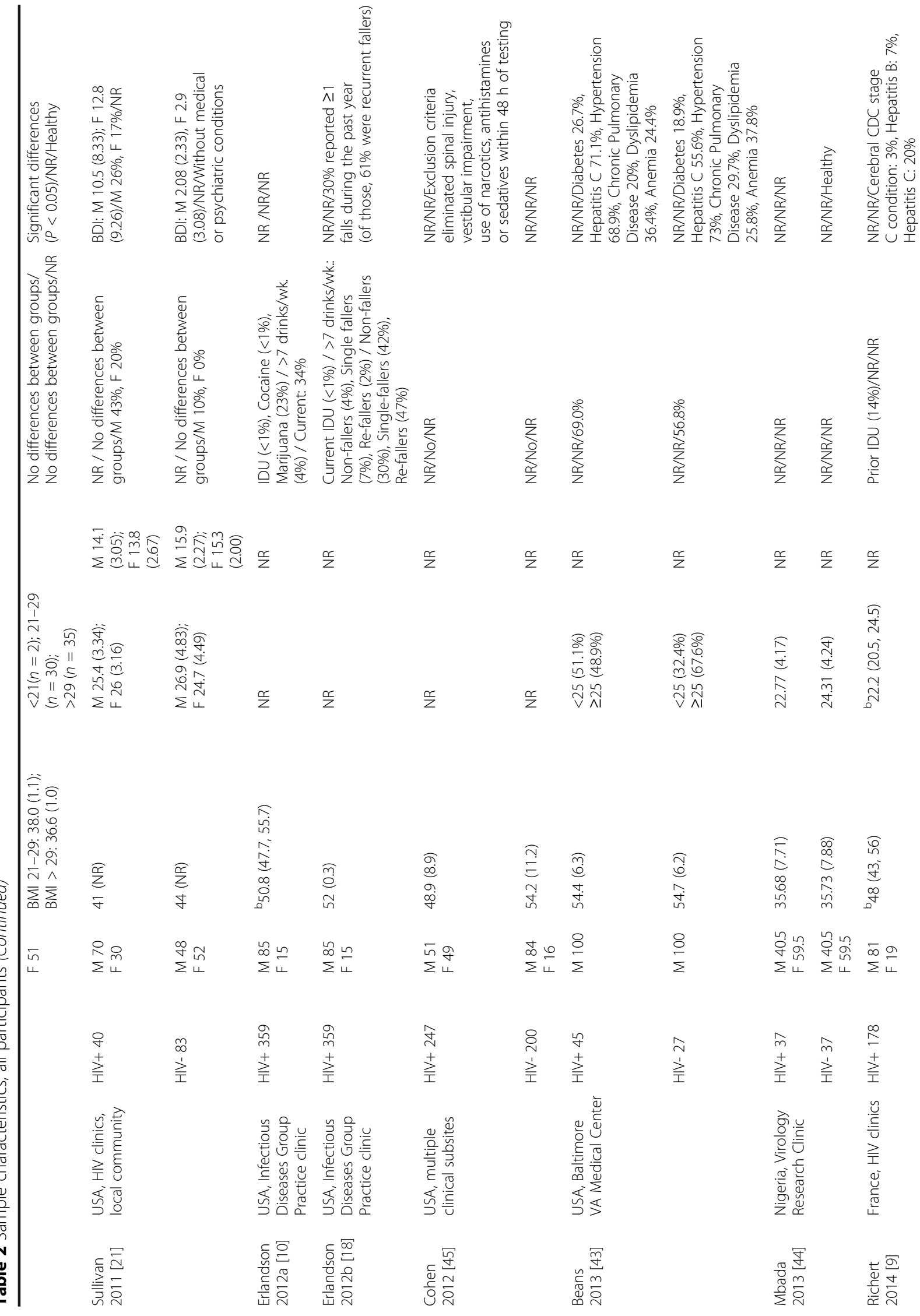




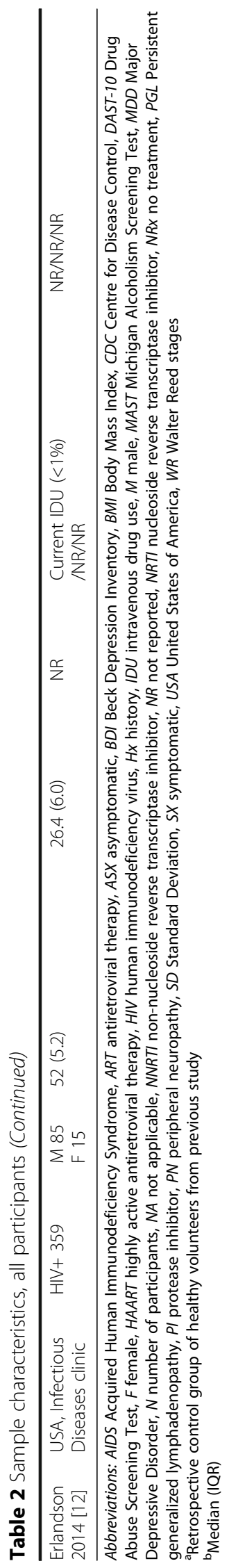


Table 3 Sample characteristics, PLHIV

\begin{tabular}{|c|c|c|c|c|}
\hline Study ID & Disease staging & $\begin{array}{l}\text { CD4 cell count, } \\
\text { cells } / \mathrm{mm}^{3} \text { (SD) }\end{array}$ & Viral load (SD) & Treatment \\
\hline $\begin{array}{l}\text { Trenkwalder } \\
1992[46]\end{array}$ & $\begin{array}{l}\text { WR I-II }(N=17) ; \text { WR III-V } \\
(N=19) ; \text { WR VI }(N=14)\end{array}$ & NR & NR & NR \\
\hline $\begin{array}{l}\text { Arendt } \\
1994[47]\end{array}$ & 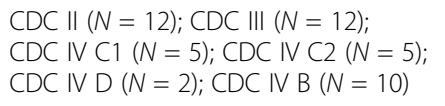 & NR & NR & NR \\
\hline $\begin{array}{l}\text { Beckley } \\
1998[50]\end{array}$ & $\begin{array}{l}\text { ASX }(N=2) ; C D C \text { Stage A }(N=2) ; \\
\text { CDC Stage B }(N=2) ; C D C \text { Stage } \\
C(N=3)\end{array}$ & $\begin{array}{l}\text { Range } 65-701 ; 5 \\
\text { participants had } \\
\text { AIDS-defining CD4 } \\
\text { counts }(<200)\end{array}$ & NR & $\begin{array}{l}\text { Most were on zidovudine maintenance } \\
\text { therapy }\end{array}$ \\
\hline $\begin{array}{l}\text { Bauer } \\
2005[7]\end{array}$ & $N R$ & $\begin{array}{l}\text { NRx: } 351(282) ; \\
\text { NNRTI: } 457(375) ; \\
\text { PI: } 320 \text { (200) }\end{array}$ & $\begin{array}{l}\text { HIV burden } \times 1000 \text { copies } / \mathrm{ml} \text { : } \\
\text { NRx: } 93.8 \text { (163); NNRTI: } 35.5 \\
\text { (102); Pl: } 20.1 \text { (48.2) }\end{array}$ & $\begin{array}{l}\text { NRx: } N=28 ; \text { NNRTI: } N=25 \\
\text { PI: } N=37\end{array}$ \\
\hline $\begin{array}{l}\text { Simmonds } \\
2005 \text { [49] }\end{array}$ & $\begin{array}{l}\text { Based on CD4 count } \\
\text { ASX (CD4 > 200) }(N=52) \\
\text { AIDS }(C D 4<200)(N=48)\end{array}$ & $\begin{array}{l}\text { Range } 189.83(183.27) \\
-386.36(302.39)\end{array}$ & $\begin{array}{l}\text { Virions: } \\
\text { ASX 33545.25; AIDS } \\
\text { 193401.00 }\end{array}$ & NR \\
\hline $\begin{array}{l}\text { Dellepiane } \\
2005 \text { [48] }\end{array}$ & $\begin{array}{l}\text { CDC classificationASX }(N=15) \\
\text { AIDS (group IV) }(N=15)\end{array}$ & NR & NR & NR \\
\hline $\begin{array}{l}\text { Scott } \\
2007[35]\end{array}$ & $N R$ & $408(293)$ & $\begin{array}{l}\log \text { copies } / \mathrm{ml} \\
2.18(0.94)\end{array}$ & $\begin{array}{l}\text { All were on a NRTI-based regimen, } \\
\text { with } 82 \% \text { receiving a PI as a third agent }\end{array}$ \\
\hline $\begin{array}{l}\text { Richert } \\
2011[8]\end{array}$ & CDC category C: $23 \%$ & ${ }^{a} 520(348,709)$ & $<500$ copies/ml: 83\% & $89 \%$ \\
\hline $\begin{array}{l}\text { Bauer } \\
2011[22]\end{array}$ & NR & $\begin{array}{l}\mathrm{BMI}<21: 280(52) ; \mathrm{BMI} \\
\text { 21-29: } 422(40) ; \\
\mathrm{BMI}>29: 361(64)\end{array}$ & $\begin{array}{l}\text { Log10 viral load } \\
\text { BMI <21: } 3.06(0.34) \\
\text { BMI 21-29: } 2.19 \\
(0.26) ; \mathrm{BMI}>29: 2.08(0.39)\end{array}$ & $\begin{array}{l}\text { \% no ART/NNRTI-based ART/ PI-based ART: } \\
\text { BMI <21: 38.2/26.5/35.3; BMI 21-29: } \\
\text { 31.7/26.7/ } \\
41.7 ; \mathrm{BMI}>29: 37.0 / 18.5 / 44.4\end{array}$ \\
\hline $\begin{array}{l}\text { Sullivan } \\
2011[21]\end{array}$ & NR & $\begin{array}{l}\text { M } 537.4(258.97) ; F \\
583.4(103.55)\end{array}$ & $\begin{array}{l}\text { M } 13597.6(4654.88) \\
\text { F } 4609.7 \text { (3226.36) }\end{array}$ & $\begin{array}{l}\text { HAART: } N=25 ; \text { Non-HAART: } N=6 ; \\
\text { NRx: } N=9\end{array}$ \\
\hline $\begin{array}{l}\text { Erlandson } \\
\text { 2012a [10] }\end{array}$ & $N R$ & a $551(361,768)$ & $\begin{array}{l}\text { Detectable } \\
\text { ( } \geq 48 \text { copies } / \mathrm{mL}): 5 \%\end{array}$ & NR \\
\hline $\begin{array}{l}\text { Erlandson } \\
2012 b[18]\end{array}$ & NR & $594(16)$ & $\begin{array}{l}95 \% \text { had plasma HIV-1 } \\
\text { RNA }<\text { limits of detection }\end{array}$ & $\begin{array}{l}\text { Any didanosine: Non-fallers: } 57 \text { (23); } \\
\text { Single fallers: } 10 \text { (23); Recurrent fallers: } \\
24 \text { (36) Any stavudine: Non-fallers: } 93 \text { (37); } \\
\text { Single fallers: } 22 \text { (51); Recurrent fallers: } 33 \\
\text { (50) Efavirenz: Non-fallers: } 86 \text { (34); Single } \\
\text { fallers: } 10 \text { (23); Recurrent fallers: } 22 \text { (33) }\end{array}$ \\
\hline $\begin{array}{l}\text { Cohen } \\
2012[45]\end{array}$ & $N R$ & $556.4(284)$ & $\begin{array}{l}\log _{10} \text { HIV RNA: } \\
\mathrm{a}_{3} .50(2.68,4.42)\end{array}$ & HAART: $76.9 \%$ \\
\hline $\begin{array}{l}\text { Beans } \\
2013[43]\end{array}$ & NR & ${ }^{a} 445(265,531)$ & $\begin{array}{l}\text { Non-detectable } \\
\text { (<400 copies/ml): } 91 \%\end{array}$ & Majority were receiving CART \\
\hline $\begin{array}{l}\text { Mbada } \\
2013[44]\end{array}$ & $\begin{array}{l}\text { All: Clinical stage I of HIV/AIDS } \\
\text { (ASX HIV infection, with PGL) }\end{array}$ & NR & NR & 100\% HAART \\
\hline $\begin{array}{l}\text { Richert } \\
2014[9]\end{array}$ & CDC stage C $24 \%$ & ${ }^{a} 506(340,715)$ & $\begin{array}{l}\text { HIV RNA level }<500 \\
\text { copies/ml: } 84 \%\end{array}$ & $89 \%$ on ART \\
\hline $\begin{array}{l}\text { Erlandson } \\
2014[12]\end{array}$ & NR & $594(303)$ & $\begin{array}{l}\text { HIV-1 RNA }<\text { limits } \\
\text { of detection: } 95 \%\end{array}$ & All participants taking effective cART \\
\hline
\end{tabular}

Abbreviations: AIDS acquired immunodeficiency syndrome, $A R T$ antiretroviral therapy, ASX asymptomatic, BMI Body Mass Index, $C A R T$ combination antiretroviral therapy, $C D C$ Centre for Disease Control, $F$ female, HAART highly active antiretroviral therapy, HIV human immunodeficiency virus, IQR interquartile range, $M$ male, $N$ number of participants, NA not applicable, NNRTI non-nucleoside reverse transcriptase inhibitor, NR not reported, NRTI nucleoside reverse transcriptase inhibitors, NRx no treatment, PGL Persistent generalized lymphadenopathy, PI protease inhibitor, PLHIV people living with HI, SD standard deviation, SX symptomatic, WR Walter Reed staging

${ }^{\mathrm{a}}$ Median (IQR)

as well as Way (average velocity of movement) was found to be increased in all HIV groups [48].

Sensory Organisation Test (SOT) sway strategy score was found to be lower (which is worse, as it indicates more reliance on the hip strategy as opposed to the ankle strategy) for bilateral stance (eyes closed) in PLHIV [22]. Two studies [7, 22] reported on SOT Equilibrium Quotient (EQ) and reported significant impairments in PLHIV during the most difficult SOT subtests (eyes closed or inaccurate visual input). 
Table 4 Study aims

\begin{tabular}{|c|c|c|}
\hline Study ID & Design & Aim \\
\hline Trenkwalder 1992 [46] & Cross-sectional & $\begin{array}{l}\text { To measure postural performance quantitavely in PLHIV (in different disease stages) } \\
\text { versus seronegative controls, using a force plate. }\end{array}$ \\
\hline Arendt 1994 [47] & Cross-sectional & $\begin{array}{l}\text { To determine if stance control is impaired in early versus late HIV infection, using a } \\
\text { force plate, and to compare results with the COG patterns in pyramidal or extrapyramidal disease. }\end{array}$ \\
\hline Beckley 1998 [50] & Cross-sectional & $\begin{array}{l}\text { To evaluate postural reflexes with EMG in PLHIV without obvious neurological disease, } \\
\text { in order to determine whether postural reflexes are early markers of CNS involvement. }\end{array}$ \\
\hline Bauer 2005 [7] & Cross-sectional & To assess sensorimotor function in PLHIV and seronegative controls. \\
\hline Simmonds 2005 [49] & Cross-sectional & To characterize physical performance in PLHIV, and to examine group differences by pain and fatigue. \\
\hline Dellepiane 2005 [48] & Cross-sectional & $\begin{array}{l}\text { To investigate whether posturography can detect the presence of possible disorders of } \\
\text { the vestibulo-spinal reflex. }\end{array}$ \\
\hline Scott 2007 [35] & Cross-sectional & $\begin{array}{l}\text { To determine the extent of neuromuscular activation of selected lower limb muscles of } \\
\text { male PLHIV receiving ART, and its relationship to performance in clinical functional tests. }\end{array}$ \\
\hline Richert 2011 [8] & Cross-sectional & $\begin{array}{l}\text { To provide standardized assessments of locomotor function in PLHIV, focusing on lower } \\
\text { limb muscle performance and balance, and on potential determinants of functional impairment. }\end{array}$ \\
\hline Bauer 2011 [22] & Cross-sectional & To compare balance and gait in participants who differ in BMI and the presence or absence of HIV/AIDS. \\
\hline Sullivan 2011 [21] & Cross-sectional & $\begin{array}{l}\text { To investigate whether infratentorial brain volume would be marked by regional tissue shrinkage } \\
\text { in PLHIV versus seronegative controls, and whether tissue deficits would be related to impairment } \\
\text { in postural stability or psychomotor speed, using structural MRI and quantitative tests of postural } \\
\text { stability, finger movement, psychomotor speed and dexterity. }\end{array}$ \\
\hline Erlandson 2012a [10] & Cross-sectional & To compare the FFP, SPPB, and 400-m walk in PLHIV. \\
\hline Erlandson 2012b [18] & Cross-sectional & $\begin{array}{l}\text { To determine fall-rate and -risk factors among PLHIV by correlating fall history, medical diagnoses, } \\
\text { and functional tests. }\end{array}$ \\
\hline Cohen 2012 [45] & Cross-sectional & $\begin{array}{l}\text { To determine whether PLHIV on HAART had an increased prevalence of vestibular disorders } \\
\text { versus seronegative controls, using standard screening tests of vestibular and balance function. }\end{array}$ \\
\hline Beans 2013 [43] & Cross-sectional & $\begin{array}{l}\text { To compare locomotor function in male PLHIV versus seronegative controls, and test the association } \\
\text { with aerobic exercise capacity. }\end{array}$ \\
\hline Mbada 2013 [44] & Cross-sectional & $\begin{array}{l}\text { To compare HRQOL and a performance-based measure of functional capacity between a } \\
\text { homogenous sample of clinical stage I PLHIV versus seronegative controls. }\end{array}$ \\
\hline Richert 2014 [9] & Prospective cohort & $\begin{array}{l}\text { To prospectively assess the changes in locomotor function in PLHIV over time and to evaluate the } \\
\text { determinants of variations in lower limb muscle performance. }\end{array}$ \\
\hline Erlandson 2014 [12] & Cross-sectional & To assess the impact of physical function impairments on HRQOL in PLHIV using ART. \\
\hline
\end{tabular}

Abbreviations: ART antiretroviral therapy, BMI body mass index, CNS central nervous system, COG centre of gravity, EMG electromyography, FFP Fried's Frailty Phenotype, HRQOL health-related quality of life, PLHIV people living with HIV, SPPB Short Physical Performance Battery

Meta-analyses (Figs. 2 and 3) were performed for postural sway area [47, 48]. With eyes open, asymptomatic PLHIV and controls had similar sway areas, while PLHIV with symptoms of chronic HIV disease demonstrated a significant increase. Overall, sway area was significantly increased in PLHIV (combined group of those with and without symptoms of HIV). With eyes closed, PLHIV with asymptomatic HIV infection had normal sway areas, while PLHIV with symptoms of chronic HIV disease demonstrated a significant increase. Overall, sway area was increased in PLHIV.

Thus, the observed overall treatment effect in the combined group differed across the different subgroups. Homogeneity seems to exist between the sample estimates within the subgroups $\left(I^{2}=0 \%\right.$ for all groups), while a significant interaction existed between the subgroups $\left(\mathrm{I}^{2}=86.4 \%\right.$ \& $87.9 \%$ for the two outcomes, respectively), suggesting that the population parameters estimated by the subgroups are different. It should however be noted that the conjecture about homogeneity between sample estimates in these subgroup does not necessarily mean that the presence/absence of symptoms in PLHIV fully explains the heterogeneity observed across studies. In fact, the small number of studies and sample sizes for these outcomes might not provide adequate statistical power in demonstrating heterogeneity.

A meta-analysis (Fig. 4) was done for Romberg ratio of sway velocity (sway with eyes closed/sway with eyes open) $[47,48]$. PLHIV with asymptomatic HIV infection had normal values, while PLHIV with symptoms of chronic HIV disease demonstrated a significantly larger Romberg ratio (which is worse as it indicates a higher amount of visual dependency). Overall, Romberg ratios were similar between the combined group of PLHIV and controls.

Substantial heterogeneity was found within the combined group $\left(\mathrm{I}^{2}=88 \%, p=0.004\right.$ and $\mathrm{I}^{2}=91 \%, p=0.00001$, respectively). When splitting the subgroups according to presence of symptoms, PLHIV with asymptomatic HIV infection still showed evidence of high heterogeneity and nonsignificant results regarding impairment, while symptomatic 


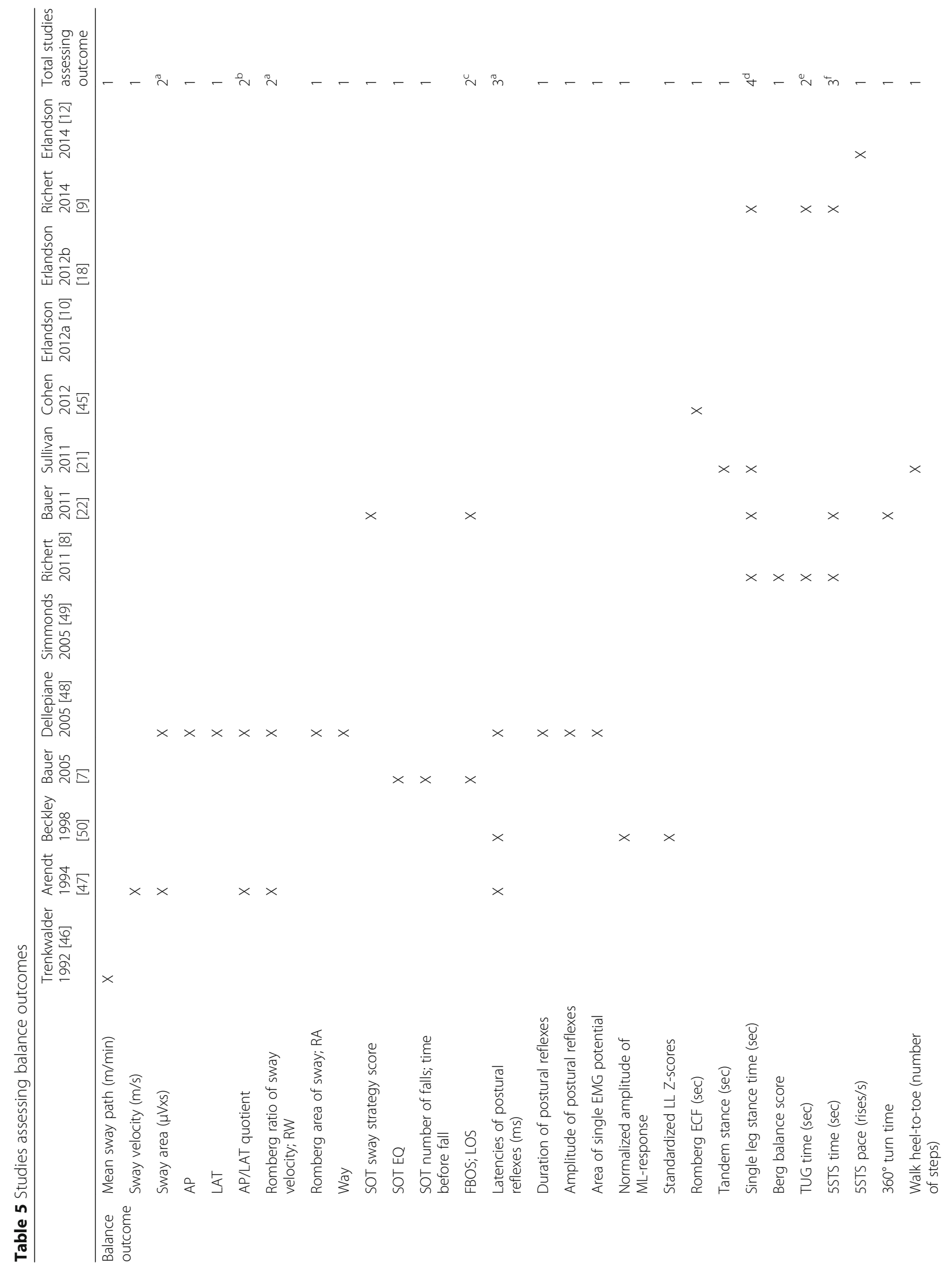




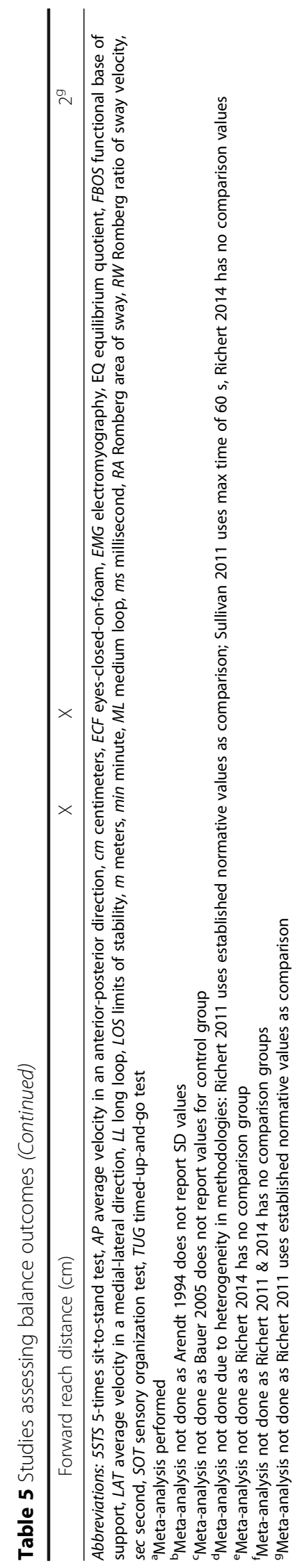




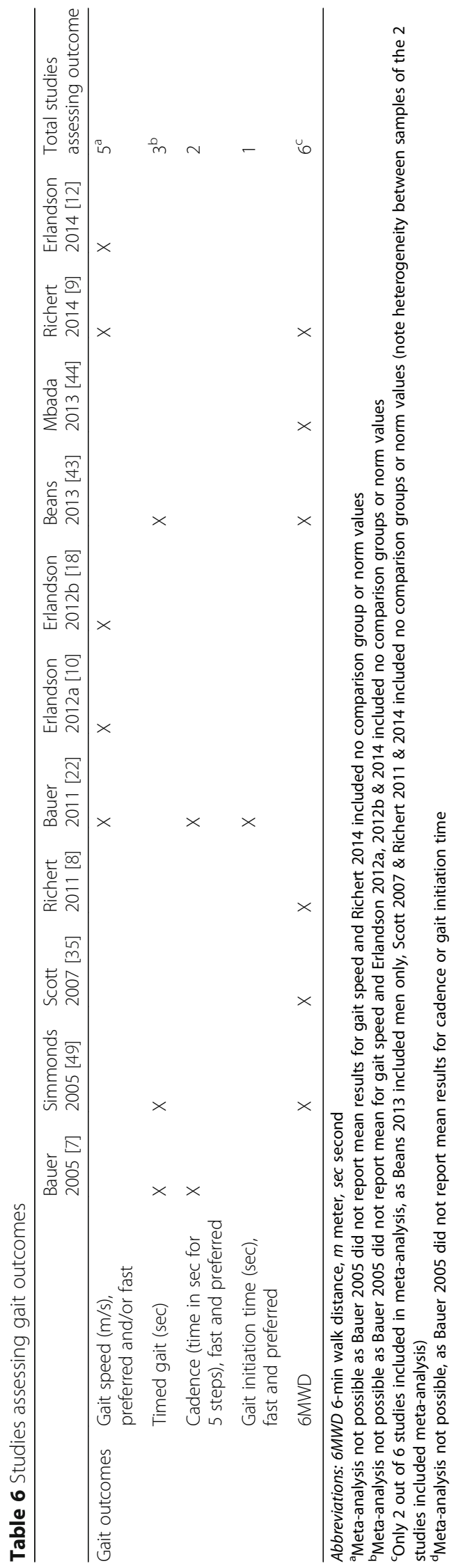


Table 7 Summary of objective balance outcomes and results

\begin{tabular}{|c|c|c|c|}
\hline Study ID & Results & Method of measurement & Outcomes assessed \\
\hline $\begin{array}{l}\text { Trenkwalder } \\
1992[46]\end{array}$ & ba & $\begin{array}{l}4 \text { conditions on force plate: Bilat stance EO + stable; } \\
\text { Bilat stance EC + stable; Bilat stance EO + foam; } \\
\text { Bilat stance EC + foam. }\end{array}$ & $\begin{array}{l}\text { Mean sway path }(\mathrm{m} / \mathrm{min}): \text { EO \& EC + } \text { foam }^{\mathrm{b}} \\
\text { (all PLHIV except WR I-II)/EC }+ \text { stable or foam } \\
\text { (all PLHIV)/All other conditions }{ }^{\text {a }}\end{array}$ \\
\hline $\begin{array}{l}\text { Arendt } \\
1994[47]\end{array}$ & $\mathrm{b},{ }_{1}$ & $\begin{array}{l}2 \text { conditions on force plate: Bilateral stance EO; } \\
\text { Bilateral stance EC. }\end{array}$ & Sway velocity $(\mathrm{m} / \mathrm{s})^{\mathrm{b}} / \mathrm{AP} / \mathrm{LAT}$ quotient ${ }^{\mathrm{a}}$ \\
\hline $\begin{array}{l}\text { Beckley } \\
1998[50]\end{array}$ & $\mathrm{ba}$ & $\begin{array}{l}\text { Leg reflexes elicited in participants while standing } \\
\text { upright on movable force plate - surface EMG } \\
\text { recordings obtained from left tibialis anterior and } \\
\text { medial gastrocnemius }\end{array}$ & $\begin{array}{l}\text { Onset latencies (SL, ML and LL) (ms) / Normalized amplitude } \\
\text { of } \mathrm{ML}^{\mathrm{a}} / \mathrm{LL} \text {-amplitude scaling (predictable }{ }^{\mathrm{a}} \text {; unpredictable }{ }^{\mathrm{b}} \text { ) }\end{array}$ \\
\hline $\begin{array}{l}\text { Bauer } \\
2005[7]\end{array}$ & $\mathrm{ba}$ & $\begin{array}{l}\text { 1) SOT, } 3 \text { conditions: EO, EC, inaccurate visual input } \\
\text { 2) Forward/backward lean tests } \\
\text { 3) (Single-leg stance test) }\end{array}$ & $\begin{array}{l}\text { 1) SOT, for each condition: EQ. (EO }{ }^{a}, E^{b} \text {, inaccurate }{ }^{a} \text { ) } \\
\text { /Number of falls } s^{a} / \text { Time before a fall (seconds) } \\
\text { 2) FBOS (Lean amplitude/ft length) } \\
\text { 3) (Single Leg Stance time (s) - results not presented) }\end{array}$ \\
\hline $\begin{array}{l}\text { Simmonds } \\
2005[49]\end{array}$ & $\mathrm{a}$ & $\begin{array}{l}\text { Loaded forward reach } \\
\text { Unloaded forward reach }\end{array}$ & Distance reached $(\mathrm{cm})^{a}$ \\
\hline $\begin{array}{l}\text { Richert } \\
2011[8]\end{array}$ & ac & $\begin{array}{l}\text { 1) BBS } \\
\text { 2) TUG test } \\
\text { 3) FR test } \\
\text { 4) SLS, EC } \\
\text { 5) } 5 S T S\end{array}$ & $\begin{array}{l}\text { 1) Berg score } \\
\text { 2) TUG time }(\mathrm{sec})^{a} \\
\text { 3) Reach distance }(\mathrm{cm})^{a} \\
\text { 4) SLS time }(\mathrm{sec})^{c} \\
\text { 5) } 5 \mathrm{STS} \text { time }(\mathrm{sec})^{c}\end{array}$ \\
\hline $\begin{array}{l}\text { Dellepiane } \\
2005 \text { [48] }\end{array}$ & $\mathrm{b}, \mathrm{a}$ & $\begin{array}{l}\text { 1) Static posturography: Romberg's position on } \\
\text { force plate; EO \& EC } \\
\text { 2) Dynamic posturography: EO \& EC; leg reflexes } \\
\text { elicited via sudden tilts of moveable force plate, } \\
\text { EMG recorded }\end{array}$ & 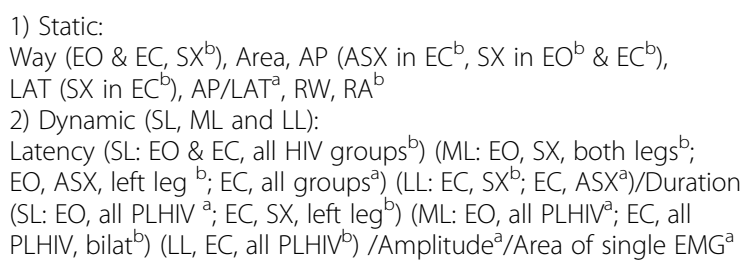 \\
\hline $\begin{array}{l}\text { Bauer } \\
2011[22]\end{array}$ & $\mathrm{b}, \mathrm{a}$ & $\begin{array}{l}\text { 1) SOT, } 3 \text { conditions: EO, EC, inaccurate visual input } \\
\text { 2) Forward/backward lean tests } \\
\text { 3) SLS test } \\
\text { 4) } 360 \text {-degree turn test } \\
\text { 5) } 5 S T S \text { test }\end{array}$ & $\begin{array}{l}\text { 1) SOT: Dependent variables calculated for each condition were: } \\
E Q \text { (EC, inaccurate input } t^{b} \text { ) } \\
\text { Sway strategy score }\left(E C^{b}\right) \\
\text { 2) LOS (lean amplitude/ft length) } \\
\text { 3) SLST time (seconds) (only obese PLHIV, non-preferred leg }{ }^{b} \text { ) } \\
\left.\text { 4) } 360 \text { deg. turn time (seconds) (only obese PLHIV } V^{b}\right) \\
\text { 5) } 5 S T S \text { time (seconds) }\end{array}$ \\
\hline $\begin{array}{l}\text { Sullivan } \\
2011[21]\end{array}$ & $\mathrm{b}, \mathrm{a}$ & $\begin{array}{l}\text { Walk-a-Line Battery. Conditions: Stand Heel-to-Toe; } \\
\text { Walk Heel-to-Toe; and SLS. }\end{array}$ & $\begin{array}{l}\text { 1) Stand Heel-to-Toe time (seconds) } \\
\text { 2) SLS time (seconds) (non-preferred leg }{ }^{\mathrm{b}} \text { ) } \\
\text { 3) Walk-Heel-to-Toe - number of steps out of } 10\left(\mathrm{EC}^{\mathrm{b}}\right)\end{array}$ \\
\hline $\begin{array}{l}\text { Cohen } \\
2012[45]\end{array}$ & c & $\begin{array}{l}\text { Romberg tests on stable and on foam, } 4 \text { conditions: } \\
E O+\text { stable, } E C+\text { stable, } E O+\text { foam, } E C+\text { foam. }\end{array}$ & Romberg time, EC + foam (seconds) ${ }^{c}$ \\
\hline $\begin{array}{l}\text { Erlandson } \\
\text { 2012a [10] }\end{array}$ & c & Tandem stand and 5STS as part of SPPB & $\begin{array}{l}\text { 5STS time (part of SPPB score })^{c} / \text { Tandem stance time } \\
(\text { part of SPPB score) })^{c}\end{array}$ \\
\hline $\begin{array}{l}\text { Erlandson } \\
2012 b[18]\end{array}$ & c & Tandem stand and 5STS as part of SPPB & $\begin{array}{l}\text { 5STS time (part of SPPB score) })^{c} / \text { Tandem stance time } \\
(\text { part of SPPB score })^{c}\end{array}$ \\
\hline $\begin{array}{l}\text { Richert } \\
2014[9]\end{array}$ & c & $\begin{array}{l}\text { 1) } 5 S T S \text { test } \\
\text { 2) TUG test } \\
\text { 3) SLS test }\end{array}$ & $\begin{array}{l}\text { 1) } 5 \text { STS time (seconds) } \\
\text { 2) TUG time (seconds) } \\
\text { 3) SLS time (seconds) })^{c}\end{array}$ \\
\hline $\begin{array}{l}\text { Erlandson } \\
2014[12]\end{array}$ & c & 5STS & 5STS pace $(\text { rises } / \mathrm{s})^{c}$ \\
\hline
\end{tabular}

Outcomes included in meta-analyses are not included in this table

Abbreviations: 5STS 5-times-sit-to-stand, AP Average velocity in anterior-posterior direction, ASX asymptomatic; BBS Berg Balance Scale, Bilat bilateral, COP center of pressure, deg. degree, $E C$ eyes closed, $E M G$ electromyography, $E O$ eyes open, $E Q$ equilibrium quotient, $F B O S$ functional base of support, $F R$ functional reach, $L A T$ average velocity in medial-lateral direction, LL long loop, LOS limits of stability, ML medium loop, PLHIV people living with HIV, RW Romberg index reported to way = ratio of way with EO \& EC, RA Romberg index reported to area = ratio of area with EO \& EC, SL short loop, SLS single leg stance, SOT sensory organization test, SX symptomatic, TUG timed-up-and-go

a no significant difference between PLHIV and controls

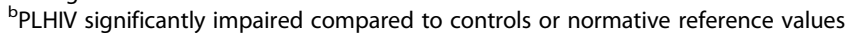

${ }^{\mathrm{C}}$ No comparison provided/impairment quantified by reporting proportion of PLHIV with deficits 
Table 8 Summary of objective gait outcomes and results

\begin{tabular}{|c|c|c|c|}
\hline Study ID & Results & Method of assessment & Spatiotemporal outcome \\
\hline Bauer 2005 [7] & a & 8-m walk (preferred and fast) & $\begin{array}{l}\text { Gait speed: time (sec) to cover distance } \\
\text { Cadence (time in sec for } 5 \text { steps) }\end{array}$ \\
\hline Simmonds 2005 [49] & b & 50-ft (15.24-m) walk (preferred and fast) & Gait speed: time (sec) to cover distance ${ }^{\mathrm{b}}$ \\
\hline Scott 2007 [35] & b & 6MWD & Distance covered $(m)$ in 6 min $^{\mathrm{b}}$ \\
\hline Richert 2011 [8] & c & 6MWD & Distance covered $(m)$ in 6 min $^{c}$ \\
\hline Bauer 2011 [22] & b & 8-m walk (preferred and fast) & $\begin{array}{l}\text { Preferred }{ }^{b} \text { and fast gait initiation time (sec) } \\
\text { Fast }{ }^{\mathrm{b}} \text { and preferred gait speed (m/s) } \\
\text { Fast and preferred cadence (time in sec for } 5 \text { steps) }\end{array}$ \\
\hline Erlandson 2012a [10] & c & $\begin{array}{l}\text { 4-m walk as part of SPPB } \\
400-m \text { walk (fast) }\end{array}$ & $\begin{array}{l}\text { Only presented as part of SPPB score } \\
\text { Gait speed }(\mathrm{m} / \mathrm{s})^{c}\end{array}$ \\
\hline Erlandson 2012b [18] & c & $\begin{array}{l}\text { 1) } 4-m \text { walk as part of SPPB } \\
\text { 2) } 400-m \text { walk (fast) }\end{array}$ & $\begin{array}{l}\text { 1) Only presented as part of SPPB score } \\
\text { 2) Gait speed }(\mathrm{m} / \mathrm{s})^{c}\end{array}$ \\
\hline Beans 2013 [43] & $\mathrm{d}_{,} \mathrm{a}$ & $\begin{array}{l}\text { 1) } 6 \mathrm{MWD} \\
\text { 2) } 400-\mathrm{m} \text { long distance corridor walk }\end{array}$ & $\begin{array}{l}\text { 1) Distance covered }(m) \text { in } 6 \text { min }^{a} \\
\text { 2) Gait speed: time (sec) to cover distance }\end{array}$ \\
\hline Richert 2014 [9] & b & $\begin{array}{l}\text { 1) } 6 \mathrm{MWD} \\
\text { 2) } 10-\mathrm{m} \text { walk }\end{array}$ & $\begin{array}{l}\text { 1) Distance covered }(m) \text { in } 6 \text { min }^{b} \\
\text { 2) Gait speed }(\mathrm{m} / \mathrm{s})\end{array}$ \\
\hline Erlandson 2014 [12] & c & 400-m walk (fast pace) & Gait speed $(\mathrm{m} / \mathrm{s})^{c}$ \\
\hline
\end{tabular}

Outcomes included in meta-analyses are not included in this table

Abbreviations: $6 M W D 6$ min walk distance, $m$ meters, min minutes, sec seconds, SPPB short physical performance battery

${ }^{a}$ No significant difference between PLHIV and controls

${ }^{b}$ PLHIV significantly impaired compared to controls or normative reference values

cNo comparison provided/impairment quantified by reporting proportion of PLHIV with deficits

${ }^{\mathrm{d} C o n t r o l s ~ p e r f o r m e d ~ w o r s e ~}$

PLHIV produced no evidence of heterogeneity $\left(\mathrm{I}^{2}=0 \%\right)$ whilst showing significant impairment for this outcome.

The high heterogeneity that exists particularly in the asymptomatic subgroup of PLHIV might be attributed to differences in the study populations used by the two studies. Differences existed in the sample sizes used (36 asymptomatic PLHIV in Arendt (1994) [47] versus only 15 in Dellepiane et al. (2005) [48]). Also, the age of the asymptomatic participants in these studies differed (mean of 36.33 versus 28 years). Finally, although both studies had similar definitions of "symptomatic" participants, only
Arendt (1994) further classified the asymptomatic group into CDC disease stages.

Dynamic balance Both the Berg Balance Scale [8] and Timed-Up-And-Go (TUG) test $[8,9]$ were normal in PLHIV. For 5-Times-Sit-To-Stand (5STS) time, one study [22] found no group differences, while another [8] reported poor performance in PLHIV. The prospective cohort [9] reported an impaired 5STS time at baseline, and that 31\% of PLHIV had a decline in performance over 1 year that was greater than the empirically defined threshold. Only

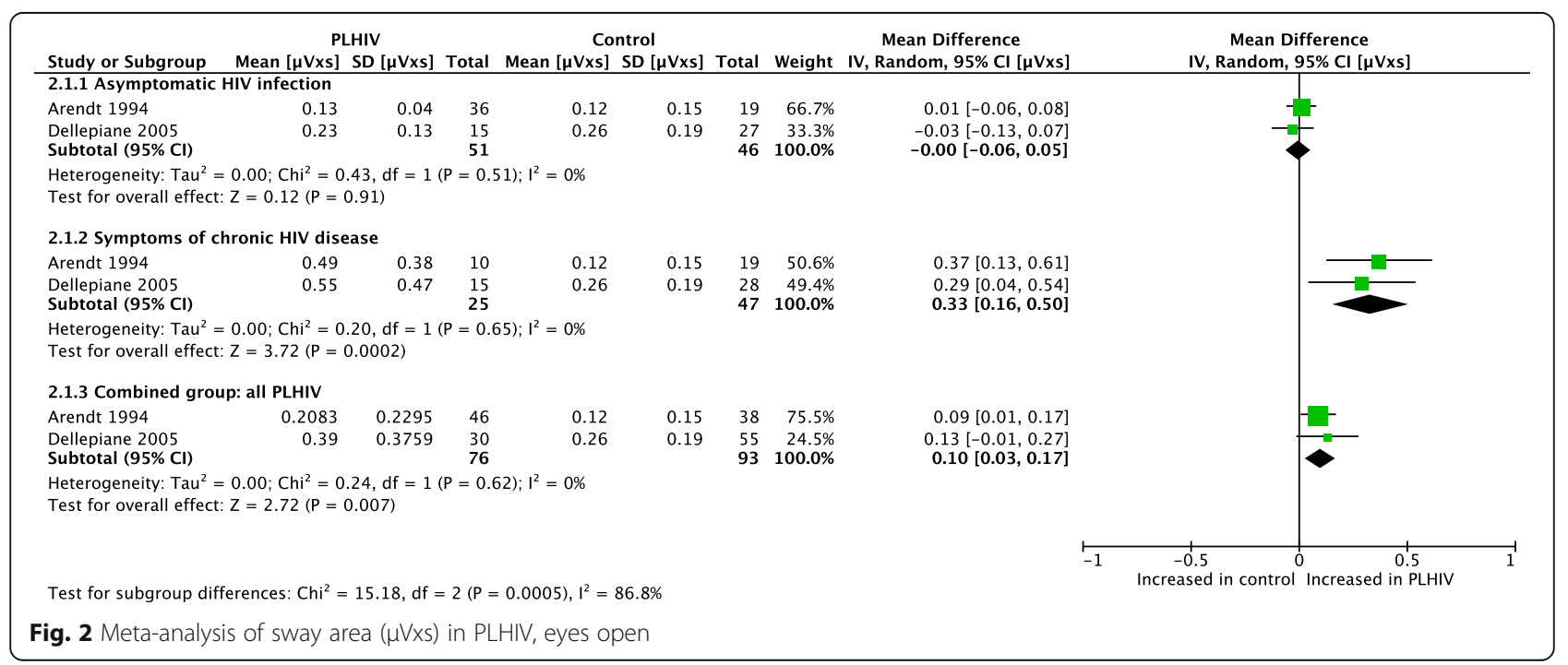




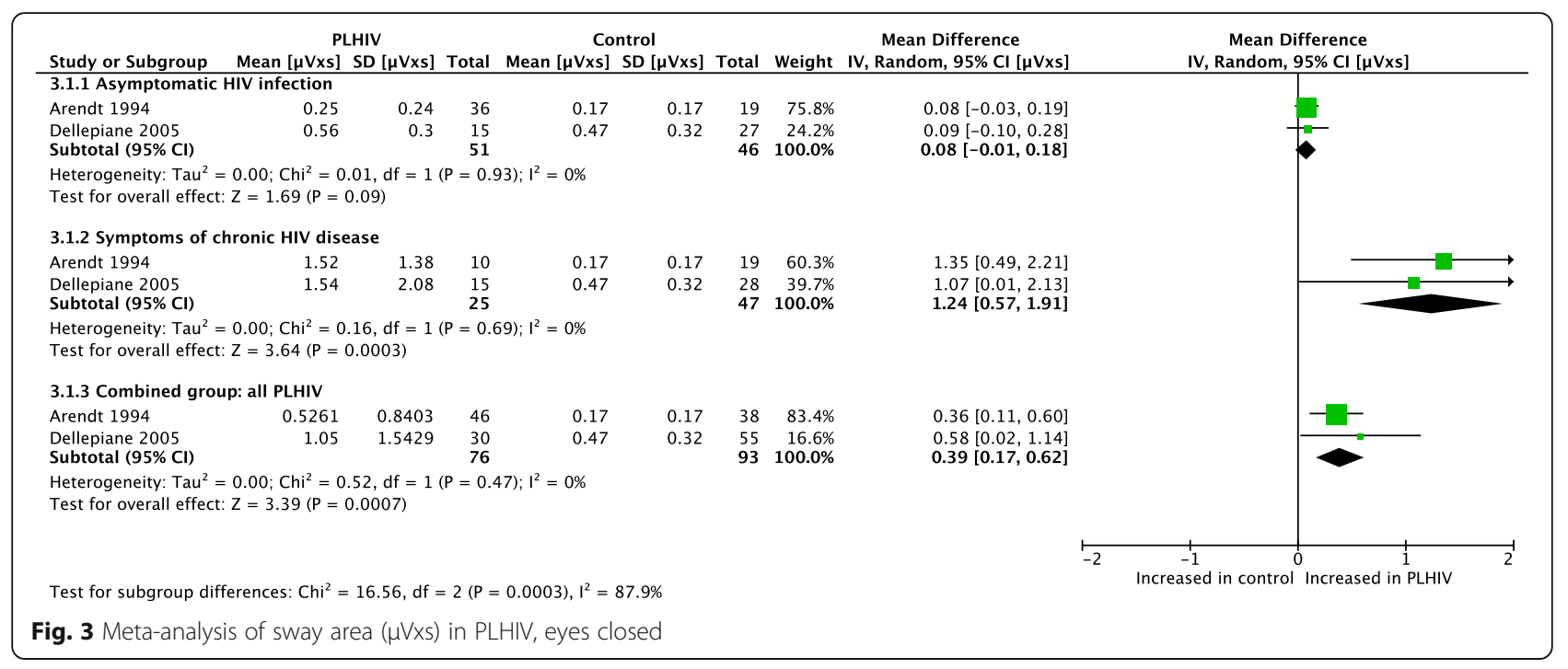

PLHIV who were also obese performed worse in the 360Degree-Turn test [22]. Walk-Heel-To-Toe was significantly impaired in PLHIV with eyes closed [21]. Two studies [8, 49] evaluated forward-reach distance, with no significant deficits noted.

The Functional Base of Support (FBOS) or Limits of Stability (LOS) tests were assessed by two studies $[7,22]$; both reported significant impairments in all PLHIV.

Duration of postural reflexes was assessed by one study [48]. With eyes closed, there was a significant reduction for medium loop (ML) duration and long loop (LL) duration in all HIV groups. Amplitude of postural reflexes and area of single electromyography (EMG) potential were normal in PLHIV [48]. Neurologically intact PLHIV showed abnormal regulation of postural reflexes (LL amplitude scaling) under unpredictable, but not predictable, perturbations [50].

Meta-analyses were conducted for postural sway latencies [47, 48, 50] (Figs. 5, 6, 7, 8 and 9). For the left leg, short loop (SL) latencies for combined PLHIV groups were normal, with significantly increased values only in PLHIV with symptoms of chronic HIV disease upon further analysis. These findings were similar for the right leg. ML latencies, only assessed in two of the studies $[48,50]$ and only for the left leg, were significantly increased in combined PLHIV groups. In both legs, LL latencies were significantly increased in symptomatic, but not asymptomatic, PLHIV. The combined PLHIV group still showed a significant increase in LL latencies.

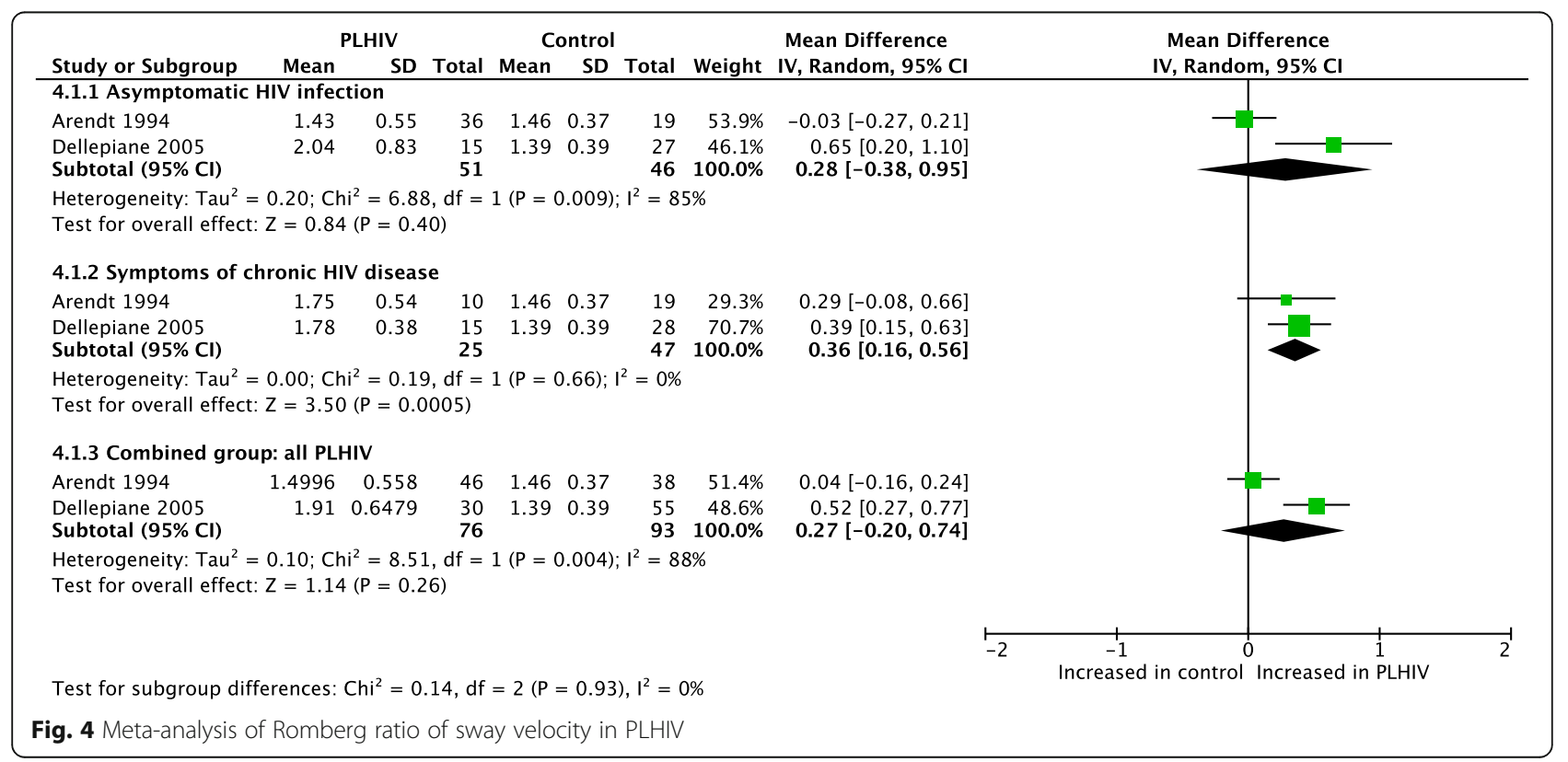




\begin{tabular}{|c|c|c|c|c|c|c|c|c|c|c|c|c|}
\hline Study or Subgroup & $\begin{array}{r}\text { PL } \\
\text { Mean }[\mathrm{ms}]\end{array}$ & $\begin{array}{l}\text { HIV } \\
\text { SD [ms] }\end{array}$ & & $\begin{aligned} \text { Con } & \\
\text { Mean }[\mathrm{ms}] \mathrm{s} & \end{aligned}$ & trol & Total & Weight & \multirow[t]{2}{*}{$\begin{array}{l}\text { Mean Difference } \\
\text { IV, Random, } 95 \% \mathrm{CI}[\mathrm{ms}]\end{array}$} & \multicolumn{4}{|c|}{$\begin{array}{c}\text { Mean Difference } \\
\text { IV, Random, } 95 \% \mathrm{CI}[\mathrm{ms}]\end{array}$} \\
\hline \multicolumn{12}{|c|}{ 5.1.1 Asymptomatic HIV infection } & \\
\hline Arendt 1994 & 32.2 & 5.2 & 36 & 32.7 & 3.7 & 19 & $51.1 \%$ & $-0.50[-2.88,1.88]$ & & & & \\
\hline $\begin{array}{l}\text { Dellepiane } 2005 \\
\text { Subtotal }(95 \% \mathrm{CI})\end{array}$ & 46.7 & 6 & $\begin{array}{l}15 \\
\mathbf{5 1}\end{array}$ & 39.4 & 3.2 & $\begin{array}{l}27 \\
46\end{array}$ & $\begin{array}{r}48.9 \% \\
100.0 \%\end{array}$ & $\begin{array}{r}7.30[4.03,10.57] \\
3.32[-4.33,10.96]\end{array}$ & & & & \\
\hline \multicolumn{13}{|c|}{$\begin{array}{l}\text { Heterogeneity: } \text { Tau }^{2}=28.29 ; \mathrm{Chi}^{2}=14.31, \mathrm{df}=1(P=0.0002) ; I^{2}=93 \% \\
\text { Test for overall effect: } Z=0.85(P=0.40)\end{array}$} \\
\hline \multicolumn{13}{|c|}{ 5.1.2 Symptoms of chronic HIV disease } \\
\hline Arendt 1994 & 43.6 & 16.2 & 10 & 32.7 & 3.7 & 19 & $59.0 \%$ & $10.90[0.72,21.08]$ & & & - & \\
\hline $\begin{array}{l}\text { Dellepiane } 2005 \\
\text { Subtotal }(95 \% \mathrm{Cl})\end{array}$ & 55.8 & 24 & $\begin{array}{l}15 \\
25\end{array}$ & 39.4 & 3.2 & $\begin{array}{l}28 \\
47\end{array}$ & $\begin{array}{r}41.0 \% \\
100.0 \%\end{array}$ & $\begin{array}{l}16.40[4.20,28.60] \\
13.16[5.34,20.97]\end{array}$ & & & & \\
\hline \multicolumn{13}{|c|}{$\begin{array}{l}\text { Heterogeneity: } \mathrm{Tau}^{2}=0.00 ; \mathrm{Chi}^{2}=0.46, \mathrm{df}=1(\mathrm{P}=0.50) ; \mathrm{I}^{2}=0 \% \\
\text { Test for overall effect: } Z=3.30(P=0.0010)\end{array}$} \\
\hline \multicolumn{13}{|c|}{ 5.1.3 Combined group: all PLHIV } \\
\hline Arendt 1994 & 34.6783 & 9.9037 & 46 & 32.7 & 3.7 & 38 & $35.2 \%$ & $1.98[-1.12,5.07]$ & & & $=$ & \\
\hline Beckley 1998 & 38.7 & 3.2 & 9 & 43.2 & 3.4 & 10 & $35.4 \%$ & $-4.50[-7.47,-1.53]$ & & -1 & & \\
\hline Dellepiane 2005 & 51.25 & 17.8007 & 30 & 39.4 & 3.2 & $\begin{array}{r}55 \\
103\end{array}$ & $29.4 \%$ & $11.85[5.42,18.28]$ & & & & \\
\hline Subtotal $(95 \% \mathrm{Cl})$ & & & 85 & & & 103 & $100.0 \%$ & $2.59[-4.94,10.13]$ & & & & \\
\hline \multicolumn{13}{|c|}{$\begin{array}{l}\text { Heterogeneity: } \mathrm{Tau}^{2}=39.48 ; \mathrm{Chi}^{2}=23.46, \mathrm{df}=2(\mathrm{P}<0.00001) ; \mathrm{I}^{2}=91 \% \\
\text { Test for overall effect: } Z=0.67(\mathrm{P}=0.50)\end{array}$} \\
\hline \multirow{2}{*}{\multicolumn{13}{|c|}{ Test for subgroup differences: $\mathrm{Chi}^{2}=4.47, \mathrm{df}=2(\mathrm{P}=0.11), \mathrm{I}^{2}=55.3 \%$}} \\
\hline & & & & & & & & & & & & \\
\hline \multicolumn{13}{|c|}{ Fig. 5 Meta-analysis of left leg postural reflex latencies in PLHIV: short loop latencies (ms) } \\
\hline
\end{tabular}

Gait Gait speed was assessed in eight studies [7, 9, 10, 12, 18, 22, 43, 49]. PLHIV demonstrated slowing of fast gait speeds [18, 43, 49]. One study [7] found no significant differences between PLHIV and controls, regardless of pace.

Meta-analysis [44, 49] (Fig. 10) indicated that 6-Minute Walk Distance (6MWD) was significantly shorter (worse) in PLHIV compared to controls. The likelihood of high heterogeneity in this meta-analysis should be considered $\left(\mathrm{I}^{2}=65 \%, p=0.09\right)$ and might be due to the use of historical controls in one study [49] and differences in disease staging between the two studies. Among the un-pooled studies, three reported a decreased (worse) 6MWD [8, 9, 35], and one study found no impairment in PLHIV [43]. One study reported no impairments in PLHIV in cadence [7] and another reported that only PLHIV who were also obese were significantly impaired [22]. This study also reported that PLHIV had significantly delayed (worse) normal gait initiation time.

Falls One study [50] reported that fall incidence during unpredictable perturbations was similar in PLHIV versus controls. Similarly, another study [7] found no group differences in falls during SOT conditions. In contrast, one study reported a similar fall rate in middle-aged PLHIV (mean 52.0 years) and seronegative older adults ( $\geq 65$ years) [18]. Impaired balance was a major associated factor. In addition, recurrent fallers had significantly slowed gait versus non-fallers. Furthermore, in a prospective cohort [9], it was reported that $12 \%$ of PLHIV experienced a minimum of one fall in the previous year. In PLHIV with recurrent falls, baseline 5STS time and 6MWD were significantly impaired, compared to non-fallers.

Measurement conditions and task difficulty Twelve studies included some form of increasing task difficulty, such as different visual input, stable versus unstable support surfaces, decreased base of support, predictable and unpredictable external perturbations, and walking at preferred versus fast gait speeds. Of these, nine (75\%) demonstrated that both balance and gait impairments were more evident in more difficult task conditions, when comparing PLHIV to controls [7, 10, 18, 21, 22, 45, 46, 49, 50].

Disease severity Fifteen studies reported on the relationship between HIV-disease severity and locomotor performance. Of these, eight (53\%) indicated a relationship between HIV-disease severity and impairments [7, 8, 10, $35,46-48,50]$. In contrast, seven studies (46\%) found no significant differences based on CD4 counts or viral loads $[9,21,22,43,45,49,50]$.

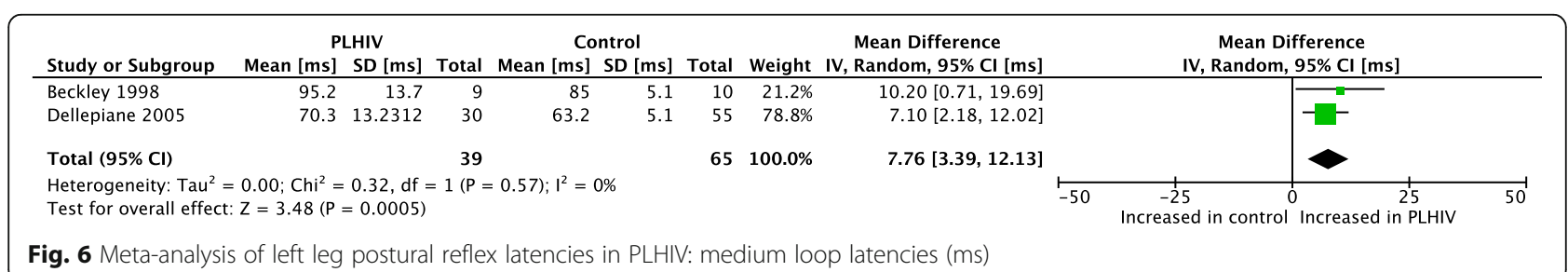




\begin{tabular}{|c|c|c|c|c|c|c|c|c|c|c|c|c|}
\hline Study or Subgroup & $\begin{aligned} \mathrm{PL} & \\
\text { Mean }[\mathrm{ms}] & \end{aligned}$ & $\begin{array}{l}\text { LHIV } \\
\text { SD [ms] }\end{array}$ & & & \multirow{2}{*}{ Total } & \multirow{2}{*}{ Weight } & \multirow[t]{2}{*}{$\begin{array}{l}\text { Mean Difference } \\
\text { IV, Random, } 95 \% \mathrm{CI}[\mathrm{ms}]\end{array}$} & \multicolumn{4}{|c|}{$\begin{array}{c}\text { Mean Difference } \\
\text { IV, Random, } 95 \% \mathrm{CI}[\mathrm{ms}]\end{array}$} \\
\hline \multicolumn{10}{|c|}{ 5.3.1 Asymptomatic HIV infection } & & & \\
\hline Arendt 1994 & 118.7 & 14.5 & 36 & 111.9 & 14.7 & 19 & $58.3 \%$ & $6.80[-1.33,14.93]$ & & & —- & \\
\hline $\begin{array}{l}\text { Dellepiane } 2005 \\
\text { Subtotal }(95 \% \mathrm{Cl})\end{array}$ & 124.2 & 10.8 & $\begin{array}{l}15 \\
\mathbf{5 1}\end{array}$ & 121.7 & 21 & $\begin{array}{l}27 \\
46\end{array}$ & $\begin{array}{r}41.7 \% \\
100.0 \%\end{array}$ & $\begin{array}{l}2.50[-7.12,12.12] \\
5.01[-1.20,11.22]\end{array}$ & & & & \\
\hline \multicolumn{13}{|c|}{$\begin{array}{l}\text { Heterogeneity: } \text { Tau }^{2}=0.00 ; \mathrm{Chi}^{2}=0.45, \mathrm{df}=1(P=0.50) ; I^{2}=0 \% \\
\text { Test for overall effect: } Z=1.58(P=0.11)\end{array}$} \\
\hline \multicolumn{13}{|c|}{ 5.3.2 Symptoms of chronic HIV disease } \\
\hline Arendt 1994 & 128 & 14.3 & 10 & 111.9 & 14.7 & 19 & $46.1 \%$ & $16.10[5.04,27.16]$ & & & - & \\
\hline $\begin{array}{l}\text { Dellepiane } 2005 \\
\text { Subtotal }(95 \% \mathrm{Cl})\end{array}$ & 127.4 & 10.7 & $\begin{array}{l}15 \\
25\end{array}$ & 121.7 & 21 & $\begin{array}{l}28 \\
47\end{array}$ & $\begin{array}{r}53.9 \% \\
100.0 \%\end{array}$ & $\begin{array}{l}5.70[-3.78,15.18] \\
10.49[0.33,20.65]\end{array}$ & & & & \\
\hline \multicolumn{13}{|c|}{$\begin{array}{l}\text { Heterogeneity: } \mathrm{Tau}^{2}=26.48 ; \mathrm{Chi}^{2}=1.96, \mathrm{df}=1(\mathrm{P}=0.16) ; \mathrm{I}^{2}=49 \% \\
\text { Test for overall effect: } Z=2.02(\mathrm{P}=0.04)\end{array}$} \\
\hline \multicolumn{13}{|c|}{ 5.3.3 Combined group: all PLHIV } \\
\hline Arendt 1994 & 120.7217 & 14.8144 & 46 & 111.9 & 14.7 & 38 & $41.0 \%$ & $8.82[2.48,15.16]$ & & & $\longrightarrow$ & \\
\hline Beckley 1998 & 142.5 & 13.3 & 9 & 126.9 & 10.3 & 10 & $20.6 \%$ & $15.60[4.82,26.38]$ & & & & \\
\hline Dellepiane 2005 & 125.8 & 10.6878 & 30 & 121.7 & 21 & $\begin{array}{r}55 \\
103\end{array}$ & $38.4 \%$ & $4.10[-2.64,10.84]$ & & & & \\
\hline \multicolumn{13}{|c|}{$\begin{array}{l}\text { Heterogeneity: } \text { Tau }^{2}=9.56 ; \mathrm{Chi}^{2}=3.26, \mathrm{df}=2(P=0.20) ; I^{2}=39 \% \\
\text { Test for overall effect: } Z=2.93(P=0.003)\end{array}$} \\
\hline \multirow{2}{*}{\multicolumn{13}{|c|}{ Test for subgroup differences: $\mathrm{Chi}^{2}=1.05, \mathrm{df}=2(\mathrm{P}=0.59), \mathrm{I}^{2}=0 \%$}} \\
\hline & & & & & & & & & & & & \\
\hline \multicolumn{13}{|c|}{ Fig. 7 Meta-analysis of left leg postural reflex latencies in PLHIV: long loop latencies (ms) } \\
\hline
\end{tabular}

Treatment effects Seven studies reported on the relationship between ART and impairments in gait and/or balance, and none of these found any association [7-10, 21, 22, 35].

Peripheral neuropathy Five studies reported on the association between peripheral neuropathy and impairments in gait and/or balance in PLHIV, and none of these found statistically significant correlations between peripheral neuropathy and impairments of gait, dynamic balance or static balance [7, 8, 21, 46, 47].

\section{Discussion}

The aim of this review was to establish the current state of knowledge regarding objective impairments of gait and balance in PLHIV, and to emphasize those which could contribute to increased fall risk. To the authors' knowledge, this is the first work to do so. Our findings indicate that certain aspects of gait and balance are impaired in middle-aged PLHIV, resembling those proven to predict increased fall risk in elderly populations.

The methodological quality of articles ranged from fair to low, partly as a direct consequence of observational design. Earlier studies in particular had a high risk of selection bias due to omitting important information such as participant demographics and exclusion criteria. The psychometric properties of the different tests used to assess outcomes have not yet been evaluated in PLHIV; therefore, they cannot be assumed to be valid and reliable in this specific population. Balance and gait in PLHIV may be influenced by various factors apart from HIV-status.

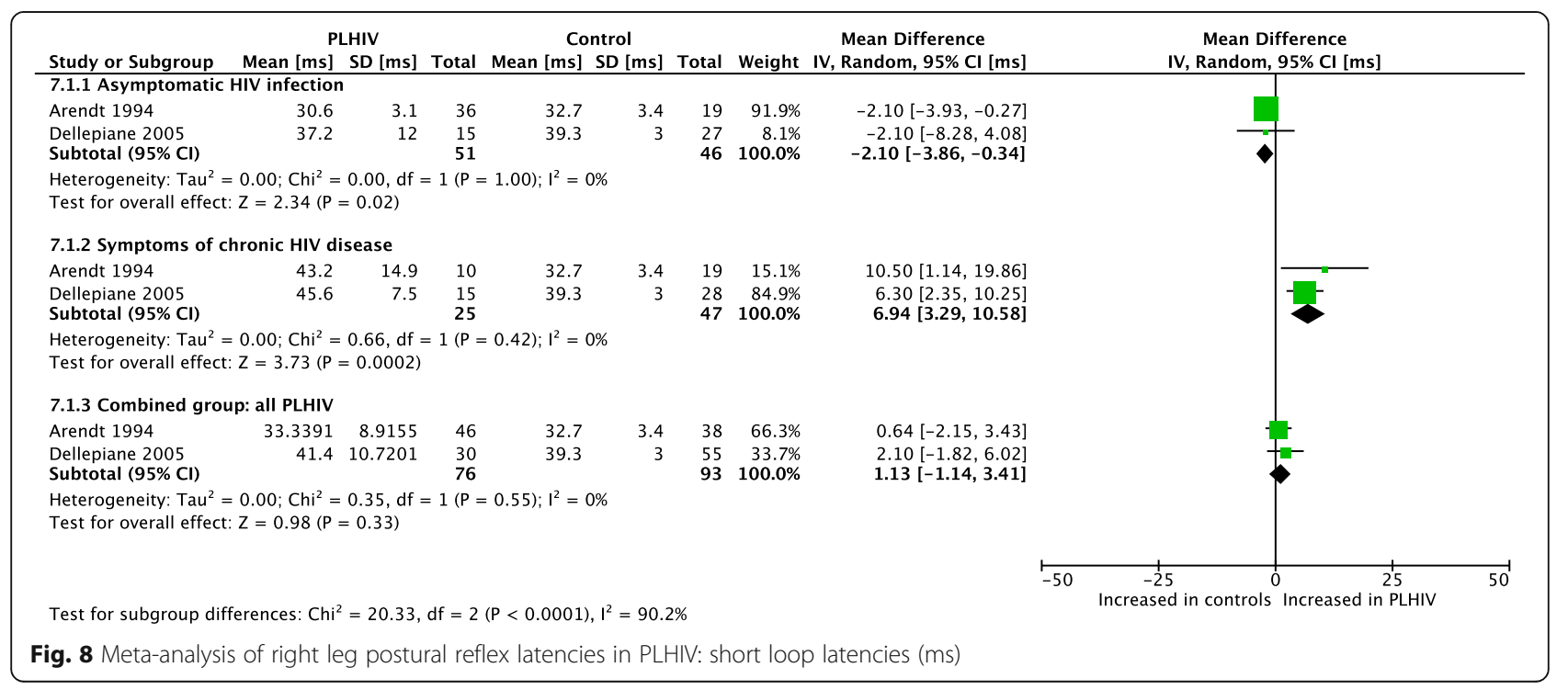




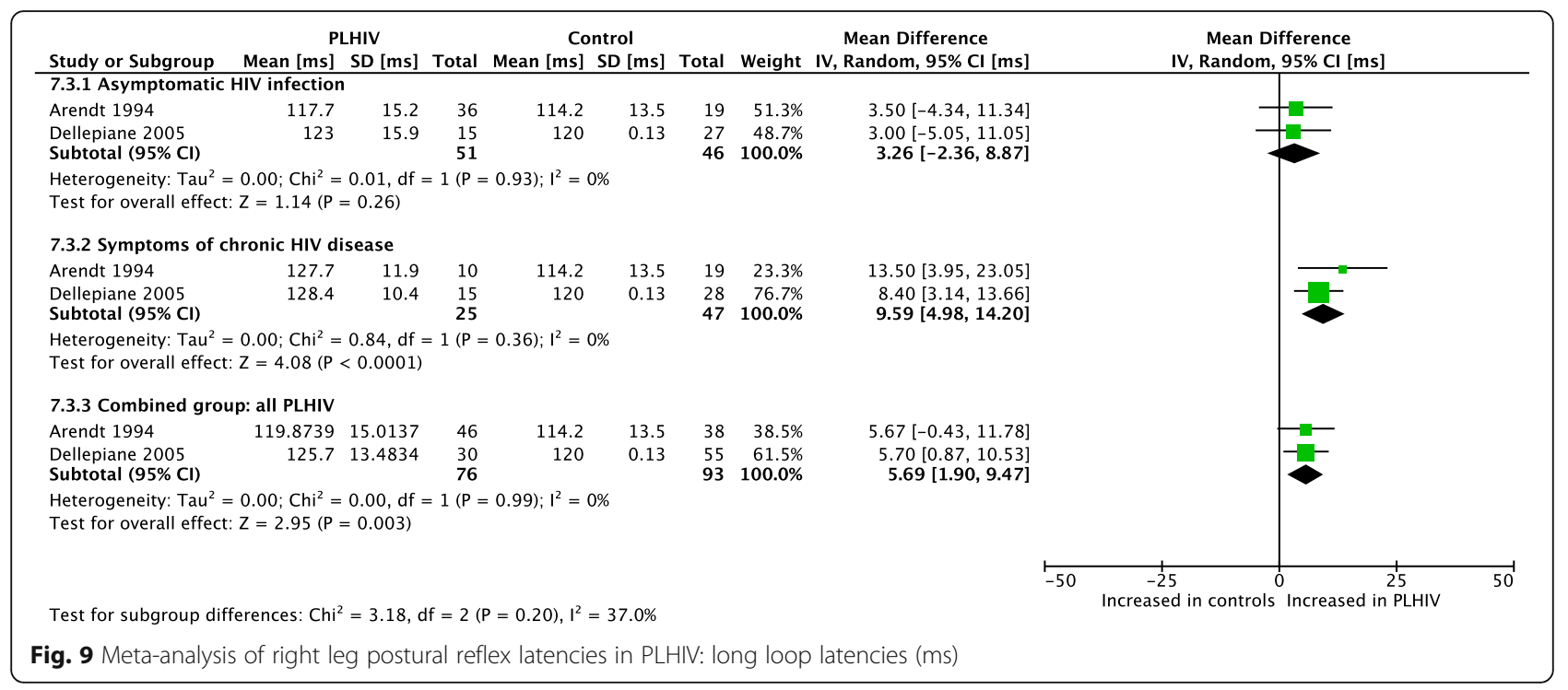

Although studies on average controlled and adjusted for many key confounders such as age, gender, BMI, markers of HIV and co-morbidities, very few reported on covariates such as level of education or adherence to treatment, and none on level of physical activity.

Various gait and balance parameters, including slowed gait speed [38], cadence [51], slowed gait initiation time [52] slowing of postural reflexes [53], and increased COP displacement and velocity [54] have been established to be associated with increased risk of falls in the elderly. Similarly, some of these variables are associated with risk of falls in PLHIV, namely slowed gait speed and impaired dynamic balance [18]. It has been reported that the best fall risk predictors in PLHIV are those proven to be predictors of fall risk in the elderly [18].

\section{Static balance}

Static balance is often quantified in terms of COP movement [55], which reflects neuromuscular control to keep the center of mass $(\mathrm{COM})$ within the base of support's limits of stability [56-58]. Increased COP movement and velocity is associated with increased fall risk in the elderly [54]. In this review, evidence of increased postural sway or velocity was found in all studies evaluating these parameters, especially under challenging conditions [46-48], and was confirmed by meta-analyses. Impaired COP sway in PLHIV with asymptomatic HIV infection may suggest early involvement of postural control due to direct infection of the CNS by HIV. However, in neurologically symptomatic PLHIV, it cannot be assumed that anatomical structures or direct HIV-involvement of the CNS causes the observed deficits [46]. Lower limb muscle impairment might impair a person's ability to correct a shift in the body's COP to effectively prevent a fall [59]. In the elderly, it has been proposed that increased COP movement may be interpreted as an increase in hip abductor muscle activity to control postural stability on the medial-lateral direction [59]. It has also been suggested that decreased postural control with larger body sway increases tibialis anterior/soleus muscle co-activation, inducing the hip-strategy to preserve balance [60]. Greater co-activation may be partly be a compensation for decreased lower limb muscle strength and power [61]. As lower limb muscle impairments occur in PLHIV, this might contribute to the impaired COP parameters observed. HIV-associated vestibular dysfunction has also been reported [62]. Vestibular disorders have a deleterious effect on postural stability [63]. However, vestibular conditions are not characterised by impaired COP excursion, but rather by an increased frequency of movement, indicating poor control of COP [63].

A lower sway strategy score (the relative amount of high-frequency ankle versus low-frequency hip movement) for bilateral stance with eyes closed was found in PLHIV, albeit only reported in a single study in this review

\begin{tabular}{|c|c|c|c|c|c|c|c|c|c|c|}
\hline Study or Subgroup & \multicolumn{3}{|c|}{ PLHIV } & \multicolumn{2}{|c|}{ Control } & \multirow{2}{*}{$\begin{array}{r}\text { Total } \\
37\end{array}$} & Weight & $\begin{array}{c}\text { Mean Difference } \\
\text { IV, Random, } 95 \% \mathrm{CI}[\mathrm{m}]\end{array}$ & \multicolumn{2}{|c|}{$\begin{array}{c}\text { Mean Difference } \\
\text { IV, Random, } 95 \% \mathrm{CI}[\mathrm{m}]\end{array}$} \\
\hline Mbada 2013 & 442.95 & 93.32 & 37 & 556.07 & 93.41 & & $41.8 \%$ & $-113.12[-155.66,-70.58]$ & $-\square-$ & \\
\hline Simmonds 2005 & 486.66 & 95.44 & 100 & 556.98 & 90.61 & 103 & $58.2 \%$ & $-70.32[-95.93,-44.71]$ & & \\
\hline Total $(95 \% \mathrm{Cl})$ & & & 137 & & & 140 & $100.0 \%$ & $-88.21[-129.59,-46.84]$ & & \\
\hline \multicolumn{9}{|c|}{$\begin{array}{l}\text { Heterogeneity: } \mathrm{Tau}^{2}=594.93 ; \mathrm{Chi}^{2}=2.85, \mathrm{df}=1(\mathrm{P}=0.09) ; \mathrm{I}^{2}=65 \% \\
\text { Test for overall effect: } Z=4.18(P<0.0001)\end{array}$} & $\begin{array}{cc}1 & 1 \\
-200 & -100 \\
\text { Decreased in PLHIV }\end{array}$ & $\begin{array}{cc}100 & 1 \\
\text { Decreased in control }\end{array}$ \\
\hline
\end{tabular}


[22], indicating a heavier reliance on the hip-strategy. In the general population, intact individuals will change their balance strategy from the normally employed ankle strategy, to relying on the hip strategy [56] when faced with more challenging conditions. Individuals with impaired balance, who already rely more heavily on the hip strategy, are less able to adapt to challenging conditions [56].

The SOT Equilibrium Quotient (EQ) is a calculation of the average COP sway, with lower EQ scores having been associated with increased fall risk in the elderly [64]. The two studies evaluating this outcome [7, 22] reported significantly lower EQ scores in PLHIV, especially with more challenging conditions.

Reduced single leg stance time is predictive of some (i.e. injurious), but not all, falls in the elderly [65]; however, the clinical value of this test might be called into question. The test might suffer from learning effects [66], leading to possible ceiling effects even in individuals with substantial impairment when only performed as a clinical test. Due to differences in the reporting of results among the included studies assessing this outcome, it is difficult to draw conclusions regarding impairment and the value of the test in PLHIV.

\section{Dynamic balance}

Dynamic balance is often assessed using dynamic posturography, which involves external perturbations being induced while a person tries to maintain an upright posture [56]. A common postural synergy in this scenario is the distal-toproximal ankle strategy, involving a short loop (SL) and medium loop (ML) response in the gastrocnemius, followed by a long loop (LL) response in the tibialis anterior $[67,68]$. Prolonged stance-stabilizing LL responses have been documented in elderly fallers [69]. Meta-analyses indicated that LL latencies were increased in symptomatic but not asymptomatic PLHIV, and upon combining all groups of PLHIV, LL latencies were still significantly increased. It is suggested that the early-observed prolonged LL latencies in PLHIV with asymptomatic HIV infection may indicate alterations in the central dopaminergic system (basal ganglia, caudatus nucleus and nigrostriatal system) [48].

Scaling of LL latency-amplitude, referring to the ability to adjust the size of posturally stabilizing reflexes and another important factor associated with falls [53], was assessed in one study [50]. Neurologically intact PLHIV showed abnormal postural reflex regulation under unpredictable, but not predictable, perturbations. Under random conditions, PLHIV automatically selected a LL response of a relatively similar size to one needed for medium perturbations. This response may not be sufficient to correct for large perturbations, leading to an increased risk of falling. However, the authors noted that the impairment in PLHIV was "mild" and did not appear clinically significant in early HIV infection.
The Limits of Stability (LOS) or Functional Base of Support (FBOS) test involves instrumented measurement of a forward leaning task and evaluates voluntary control of the center of gravity (COG). Instrumented LOS or FBOS, unlike the clinical Functional Reach test [8, 49], was impaired in PLHIV [7, 22]. Similarly, the Functional Reach test has been proven not to be an indicator for differentiating elderly fallers from non-fallers [70], while instrumented LOS is an early indicator of increased fall risk in the elderly [71]. These observations may be attributable to the differences in the task involved in the clinical versus the instrumented tests (although both assesses LOS) [71].

The 5STS test is an indicator of dynamic balance. Impaired performance was noted in two of the three studies evaluating this outcome $[8,9]$. In addition to impaired central sensorimotor components being proposed to play a role [9], impaired 5STS time also implies poor lower limb muscle performance, which is associated with falls and disability both in HIV-seronegative elderly populations and in middle-aged PLHIV $[8,18]$. Low appendicular muscle mass is prevalent in PLHIV and associated with functional impairment [72]. However, a decline in the ability of muscles to produce strength and power (dynapenia) might have a bigger contribution to functional decline in the elderly and is associated with poor chair-rise-time [73] Intra-muscular impairments, including fatty muscle infiltration, and low central activation are reported in PLHIV $[29,35,74]$ and premature expression of genes associated with muscle aging is upregulated in PLHIV [75]. Grip strength might correlate with dynapenia in the elderly [76], and an accelerated decline in grip strength has been reported in PLHIV [77].

Owing to the dichotomous assessment by clinical tests of the ability to maintain standing balance, such tests only detect impaired balance once compensation strategies fail [56]. Selection of effective compensation strategies to restore balance (especially by persons who are physically active), might hide impairments, potentially hampering the use of such tests in active individuals or at an early stage of disease [56]. Level of physical activity was not assessed by any studies included in this review; ceiling effects in the results provided by the clinical balance tests can therefore not be excluded.

Although more suited to quantification of balance, interpretation of the results of instrumented posturography is complex. Generally, an increase in COP movement is assumed to reflect impaired balance; but this may not be true [78, 79]. Due to the interdependent relationship of the underlying systems, selection of an alternative compensation strategy to maintain stance could lead to observation of either increased or decreased COP movement, which in fact would reflect optimal balance control [56]. Second, altered COP movement can result from deterioration of several underlying systems. Thirdly, COP movement is affected by 
training and learning effects, for example, individuals (and even more so those trained in sports) might be able to maintain a position very well, despite severe system deterioration, due to becoming familiar with the task or using selecting proper strategies for efficient compensation [56]. Results, especially from singular studies, must thus be considered cautiously and in the context of the assessment protocol, e.g. number of trials, and participant characteristics, such as activity level.

\section{Gait}

In this review, PLHIV exhibited impaired fast, but not preferred, gait speeds, despite being on successful HAART [10, $12,22,49]$. PLHIV who were also recurrent fallers, had an even slower fast-paced gait [18]. Gait speed is reported as a predictor of falls in geriatric populations, with a linear relationship between slow gait speed and increased fall risk often assumed [80-82]. However, a non-linear relation has also been proposed [38]. Growing evidence show that gait and cognition, specifically attention and executive function [83] are interrelated. Neurocognitive decline occur in HIV $[6,13,84-86]$, is in part associated with reduced dopaminergic function [87], and has been associated with slow gait speeds in this population [88]. Executive function, motor skills and attention/working memory are some of the domains that are affected by HIV [89]. Gait slowing is suggested to be an adaptive mechanism to prevent falls, to the effect that a slow gait speed might actually be associated with a reduced fall risk [38].

Six-Minute Walk Distance, which is actually an indicator of functional aerobic capacity, has been shown to correlate well with gait speed [90]. Meta-analyses of two studies $[44,49]$ suggests decreased 6MWD, and thus decreased gait speed under fast conditions, in PLHIV. SixMinute Walk Distance was also reported to be decreased in PLHIV in the majority of un-pooled studies assessing this outcome $[8,9,35]$ - however all of these studies used predicted values from the literature. This is of concern, as community-specific or cultural factors influence gait speed [43]. Gait initiation time was reported to be significantly slowed in PLHIV, albeit data from a single study [22]. Gait initiation time has been associated with increased fall risk in the elderly [52]. Cadence, which also has an association with gait speed and falls in the elderly [91], was assessed by two studies [7, 22], but owing to contradicting results, no firm conclusions can be drawn.

\section{Measurement conditions and task difficulty}

Evaluating performance under conditions of varying difficulty can provide more "real-life" insight into the quality of the specific underlying sensory systems [56, 92]. Studies assessing balance included in this review employed different sensory conditions, eliminating or disturbing the information of three main sensory systems. These included variations in visual input, different base-of support sizes and variations in support surfaces. For dynamic balance assessments, perturbations of varying amplitudes and predictability were induced using platform tilts. There was an overall tendency of PLHIV to perform similar to controls in easier conditions, and significantly worse with increased task difficulty. A correlation between static balance deficit and eyes closed conditions was demonstrated by clinical as well as instrumented tests $[7,22,48]$. Unstable conditions with eyes closed showed the greatest abnormalities in postural balance [45, 46]. Sullivan et al. (2011) [21] found impaired performance among PLHIV during clinical tests involving reduced base of support. Postural reflex synergies also appear to be task-dependent. Unpredictable perturbations resulted in worse dynamic balance performance [50]. It thus seems that PLHIV may have impaired response to unexpected perturbations or more complex tasks, predisposing them to falls. In the case of impairment of any of the systems contributing to postural balance, alternative compensation strategies are used by an individual to maintain postural control and orientation $[56,93]$. Sensory reweighting comes into play, i.e. the nervous system will rely on more accurate sensory input, rather than less accurate, conflicting information [94]. Individuals relying more on one particular balance system are thus less able to adapt to situations where input to that system is disturbed, and have to rely on only the remaining systems [56]. This sensory reweighting seems impaired in PLHIV. Also, impaired dual-task performance has been demonstrated in PLHIV [95], although none of the included studies assessed this condition.

All gait tests in included studies were conducted on level, unobstructed walkways. During walking, many falls occur not during normal walking, but rather when negotiation challenging terrains. Results might have been more clinically relevant had irregular or unfamiliar surfaces been assessed, especially since dynamic balance in PLHIV seem to be more impaired under challenging circumstances. However, both self-selected and fast gait speed conditions were evaluated, with group differences mostly found when comparing fast gait. It has been suggested that walking at different speeds likely influences both the noise level in human motor performance as well as dynamic error corrections [96]. Thus, impairments at fast paced conditions may indicate deficits under more challenging conditions.

\section{Disease severity}

A dose-response relationship between HIV disease severity and locomotor impairment was suggested in 53\% of studies. In addition, subgroup analyses highlighted impairments in postural reflex latencies that were inconspicuous in a combined group of all PLHIV, but became apparent in only those with symptoms of chronic HIV disease when compared to controls. However, methodologically it remains a 
challenge to attribute observed differences between PLHIV and controls directly to HIV infection, as evident from the discussion thus far. Comparison populations most likely always differ in terms of many confounding factors [8]. It cannot be assumed with certainty that observed impairments are purely related to severity of HIV infection, and the contribution of various comorbidities and opportunistic infections should be considered. This is especially true for the older studies, where eligibility criteria did not control for various confounders and comorbidities.

Treatment effects: Antiretroviral therapy (ART), combination antiretroviral therapy (CART) or highly active antiretroviral therapy (HAART)

The majority of studies reporting on treatment effect failed to find significant associations to balance or gait outcomes in PLHIV, regardless of the different combinations of drugs (terms used for combination use of ARV including ART, cART or HAART). Thus, antiretroviral therapy does not appear to be a reversing factor with regard to locomotor impairments.

\section{Peripheral neuropathy}

None of the five studies reporting on the association between peripheral neuropathy and locomotor impairments found any significant relationships. A possible explanation for balance abnormalities among PLHIV, at least for those parameters measured by the included studies, might thus indicate involvement of the central rather than peripheral nervous system $[7,8,21,46,47]$. The fact that eyes closed conditions were often necessary to elicit group differences in balance, further motivates CNS dysfunction as an underlying mechanism [7]. It is reported that deficits in infratentorial brain tissue volume and disruption of the pontocerebellar fiber system microstructure, at least in part, may contribute to locomotor impairments in PLHIV [21]. It can, however, not be concluded with certainty that no association exists between gait or balance and peripheral neuropathy in PLHIV. It is possible that peripheral neuropathy adversely affects gait and balance parameters that were not measured in these studies. For example, impairments in joint kinematics (assessed by none of the included studies in this review) have been associated with peripheral neuropathy in Type 2 diabetic patients [97].

\section{Implications for future research}

While the importance of identifying spatiotemporal deficits is acknowledged, the associated kinematic and kinetic data can provide more insight into underlying mechanisms of the observed impairments. Some locomotor impairments related to early functional decline might be too small to be detected by visual observation alone in the clinical setting [51, 98]. These subtle impairments may however have substantial consequences for the individual.
Thus, there is a need for more robust quantitative assessment, such as three-dimensional biomechanical motion analysis. We also suggest the use of dual tasking in PLHIV to assess the subtler changes in function, and adding more challenging conditions to gait assessments. Furthermore, a need exists for higher quality research. Carefully selected, representative samples will make results more homogeneous, relevant and generalizable. In addition, valuable information can be extracted from the geriatric literature that is likely to inform research in PLHIV, especially with regards to data on falls and specific movement impairments. This should be further explored, and the psychometric properties of both instrumented and clinical gait and balance assessments should be determined specifically in PLHIV. Lastly, we found the lack of studies conducted in Sub-Saharan Africa, the epicenter of the HIV epidemic, surprizing. More research is needed in developing countries to address this gap.

\section{Review limitations}

Language bias is likely in this review, as only studies published in English were considered. Another limitation of the review is that only two included articles were appraised by more than one reviewer, meaning that fifteen of the seventeen articles were scored for methodological quality by only one reviewer. In addition, ceiling effects might have hampered results from clinical tests. No studies in this review measured COM movement, with a subsequent incomplete representation of balance in PLHIV at present. Results of this review should be interpreted with caution as substantial statistical heterogeneity existed between the included studies, albeit expected, as evident in the metaanalyses (indicated by high $\mathrm{I}^{2}$ values). Due to the small number of studies per outcome, all sources of heterogeneity could not be accounted for, but some possible explanations for variation in results have been discussed. Clinical heterogeneity was evident in the majority of studies, particularly in terms of setting, sample sizes, age groups, gender distributions, and HIV-staging. A wide variety of study outcomes and measurement methods were used. Given the paucity of research on existing impairments and the optimal method of evaluating these in PLHIV, the wide variation in assessment tests used was to be expected. Although the diversity in populations, especially regarding disease definition and subgroups, might seem surprising, it must be kept in mind that HIV classification systems have evolved substantially since the earliest included study and that HAART regimes did not yet exist in those earlier periods. Furthermore, publication- and reporting biases are suspected in this review, due to many authors collaborating on different papers and the same populations possibly used in different studies. However, formal assessment using funnel plots was not possible due to the low number $(<10)$ studies assessing a similar outcome. 


\section{Conclusions}

This review found that young to middle-aged PLHIV have impairments in certain aspects of gait and balance, which are similar to those that predispose elderly seronegative populations to falls. The impairments are more pronounced during challenging conditions, might be associated with HIV disease severity, are not influenced by ART, and might not necessarily be associated with peripheral neuropathy. Results should be interpreted with caution due to the overall fair to low methodological quality, substantial heterogeneity and many outcomes being assessed by singular studies only. The effect of HIV on gait and balance parameters, and in particular biomechanical outcomes, are currently insufficiently quantified and this review provides a first step to inform future research. Further investigation involving more methodological uniformity is warranted to better identify and understand relevant locomotor impairments in PLHIV. Only then can more clinically relevant conclusions, such as appropriate strategies for fall-prevention in this population, be drawn.

\section{Additional files}

Additional file 1: Results for objective balance outcomes in PLHIV (un-pooled dependent variables). Detailed summary of individual balance outcomes assessed across studies (DOCX $53 \mathrm{~kb}$ )

Additional file 2: Results for objective gait outcomes in PLHIV (un-pooled dependent variables). Detailed summary of individual gait outcomes assessed across studies (DOCX $101 \mathrm{~kb}$ )

\section{Abbreviations}

5STS: 5-Times-Sit-To-Stand; 6MWD: Six-Minute Walk Distance; AIDS: Acquired Immune Deficiency Syndrome; AP: Average velocity in an anterior-posterior direction; ART: Antiretroviral therapy; ASX: Asymptomatic HIV infection (clinically latent phase of HIV); BMI: Body Mass Index; CART: Combination antiretroviral therapy; CD: Cannot determine; CDC: Centre for Disease Control; Cl: Confidence interval; CNS: Central nervous system; COG: Center of gravity; COM: Center of mass; COP: Center of pressure; EC: Eyes closed; EMG: Electromyography; EO: Eyes open; EQ: Equilibrium Quotient; F: Female; FBOS: Functional Base of Support; FFP: Fried's Frailty Phenotype; GIT: Gait initiation time; HAART: Highly active antiretroviral therapy; HIV: Human Immunodeficiency Virus; HRQOL: Health-related quality of life; JB: Jochen Baumeister; KB: Karina Berner; LAT: Average velocity in a medial-lateral direction; LL: Long loop; LM: Linzette Morris; LOS: Limits of Stability; M: Male; MeSH: Medical Subject Heading; ML: Medium loop; ms: Milliseconds; $\mathrm{N}$ : Number of participants; NA: Not applicable; NIH: National Institutes of Health; NNRTI: Non-Nucleoside Reverse Transcriptase Inhibitor; NR: Not reported; NRTI: Nucleoside Reverse Transcriptase Inhibitors; NRx: No treatment; PI: Protease Inhibitor; PLHIV: People living with HIV; PRISMA: Preferred Reporting Items for Systematic Reviews and Meta-Analyses; QL: Quinette Louw; RA: Romberg ratio of area; SD: Standard deviation; SL: Short loop; SOT: Sensory Organisation Test; SPPB: Short Physical Performance Battery; SX: Symptomatic (presenting with various symptoms of chronic HIV disease); TUG: Timed Up-And-Go; WR: Walter Reed staging
\end{abstract}

\section{Acknowledgements}

We gratefully acknowledge Mrs. Ingrid van der Westhuizen for her assistance with the initial searches and sourcing of articles.

\section{Funding}

Research reported in this publication was supported by the South African Medical Research Council under a Self-Initiated Research Grant, as well as by the Harry Crossley Foundation. The ongoing PhD from which this study emanated is funded by the South African Medical Research Council in terms of the National Health Scholars Programme from funds provided for this purpose by the National Department of Health. The views and opinions expressed are not those of the funders, but of the authors of the material publicized.

\section{Availability of data and materials}

The study data extracted for analyses in the current publication are available from the corresponding author on reasonable request.

\section{Authors' contributions}

$\mathrm{KB}$ and $\mathrm{QL}$ conceptualized the review and analysed the data. In addition, KB searched the databases, extracted the data, performed critical appraisal, analyzed the results and wrote the manuscript. QL assisted in designing data extraction sheets and analyzing the data. QL, LM and JB assisted in interpreting results and revising the manuscript. QL served as a second reviewer for consultation during the screening of articles for inclusion. LM served as a second reviewer in critically appraising two randomly selected articles. All authors read and approved the final manuscript.

Ethics approval and consent to participate

Not applicable.

Consent for publication

Not applicable.

Competing interests

The authors declare that they have no competing interests.

\section{Publisher's Note}

Springer Nature remains neutral with regard to jurisdictional claims in published maps and institutional affiliations.

\section{Author details}

${ }^{1}$ Division of Physiotherapy/Central Analytical Facilities (CAF) 3D Human Biomechanics Unit, Department of Rehabilitation \& Health Sciences, Faculty of Medicine and Health Sciences, Stellenbosch University, PO Box 241, Cape Town 8000, South Africa. ${ }^{2}$ Exercise \& Neuroscience Unit, Institute of Health, Nutrition and Sports Sciences, Europa-Universität Flensburg, Auf dem Campus 1, 24943 Flensburg, Germany.

Received: 29 September 2016 Accepted: 17 July 2017

Published online: 01 August 2017

\section{References}

1. Stats SA. P0302- mid-year population estimates 2016. 2016. http://www. statssa.gov.za/?page_id=1854\&PPN=P0302\&SCH=6688. Accessed 6 September 2016.

2. Bor J, Herbst AJ, Newell M-L, Bärnighausen T. Increases in adult life expectancy in rural South Africa: valuing the scale-up of HIV treatment. Science. 2013;339(6122):961-5.

3. Hontelez JAC, de Vlas SJ, Baltussen R, Newell M-L, Bakker R, Tanser F, et al. The impact of antiretroviral treatment on the age composition of the HIV epidemic in sub-Saharan Africa. AIDS. NIH Public Access; 2012;26 Suppl 1(01):S19-S30; doi: 10.1097/QAD.0b013e3283558526.

4. UNAIDS. The Gap report. 2014:2014. http://www.unaids.org/en/resources/ campaigns/2014/2014gapreport/gapreport/. Accessed 25 November 2015

5. Ortblad KF, Lozano R, Murray CJL. The burden of HIV: insights from the global burden of disease study 2010. AIDS. 2013;27(13):2003-17.

6. Banks L, Zuurmond M, Ferrand R, Kuper H. The relationship between HIV and prevalence of disabilities in sub-Saharan Africa: systematic review (FA). Trop Med Int Heal. 2015;20(4):411-29.

7. Bauer LLO, Ceballos NA, Shanley JJD, Wolfson LIL, Ceballosa N, Shanley JJD, et al. Sensorimotor dysfunction in HIV/AIDS: effects of antiretroviral treatment and comorbid psychiatric disorders. AIDS. 2005:19(5):495-502.

8. Richert L, Dehail P, Mercié P, Dauchy F, Bruyand M, Greib C, et al. High frequency of poor locomotor performance in HIV-infected patients. AIDS. $2011 ; 25(6): 797-805$. 
9. Richert $L$, Brault M, Mercié P, Dauchy F-A, Bruyand M, Greib C, et al. Decline in locomotor functions over time in HIV-infected patients. AIDS. 2014;28(10): 1441-9.

10. Erlandson K, Allshouse A, Jankowski C, Duong S, Mawhinney S, Kohrt W, et al. A comparison of functional status instruments in HIV-infected adults on effective antiretroviral therapy. HIV Clin Trials. 2012;13(6):324-34.

11. Bernard C, Dilharreguy B, Allard M, Amieva H, Bonnet F, Dauchy F, et al. Muscular weakness in individuals with HIV associated with a disorganization of the cortico-spinal tract: a multi-modal MRI investigation. PLoS One. 2013; 8(7):e66810.

12. Erlandson KKM, Allshouse AA, Jankowski CMC, Mawhinney S, Kohrt WWM Campbell TTB. Relationship of physical function and quality of life among persons aging with HIV infection. AIDS. 2014;28:1939-43.

13. Spudich S, Ances B. Neurologic complications of HIV infection: highlights from the 2013 conference on retroviruses and opportunistic infections. Top Antivir Med 2013;21(3):100-108; PMID: 23981597

14. Joska JAJ, Westgarth-Taylor J, Hoare J, Thomas KKGF, Paul R, Myer L, et al. Neuropsychological outcomes in adults commencing highly active antiretroviral treatment in South Africa: a prospective study. BMC Infect Dis. 2012;12(39):1-8. doi:10.1186/1471-2334-12-39.

15. Dorsey SG, Morton PG. HIV peripheral neuropathy: pathophysiology and clinical implications. AACN Clin Issues. 2006;17(1):30-6.

16. Ellis RJ, Rosario D, Clifford DB, McArthur JC, Simpson D, Alexander T, et al. Continued high prevalence and adverse clinical impact of human immunodeficiency virus-associated sensory neuropathy in the era of combination antiretroviral therapy. Arch Neurol. 2010;67(5):552-8. doi:10. 1001/archneurol.2010.76.

17. Simpson DM, Kitch D, Evans SR, McArthur JC, Asmuth DM, Cohen B, et al. HIV neuropathy natural history cohort study: assessment measures and risk factors. Neurology. 2006;66(11):1679-87. doi:10.1212/01.wnl.0000218303. 48113.5d.

18. Erlandson K, Allshouse A, Jankowski C, Duong S, MaWhinney S, Kohrt W, et al. Risk factors for falls in HIV-infected persons. J Acquir Immune Defic Syndr. 2012;61(4):484-9.

19. Ruiz M, Reske T, Cefalu C, Estrada J. Falls in HIV-infected patients: a geriatric syndrome in a susceptible population. J Int Assoc Provid AIDS Care. 2013; 12(4):266-9.

20. Erlandson KM, Plankey MW, Springer G, Cohen HS, Cox C, Hoffman HJ, et al. Fall frequency and associated factors among men and women with or at risk for HIV infection. HIV Med. 2016; doi:10.1111/hiv.12378.

21. Sullivan E, Rosenbloom M, Rohlfing T, Kemper C, Deresinski S, Pfefferbaum A. Pontocerebellar contribution to postural instability and psychomotor slowing in HIV infection without dementia. Brain imaging Behav. 2011;5(1): $12-24$.

22. Bauer $\mathrm{L}, \mathrm{Wu} Z$, Wolfson $\mathrm{L}$. An obese body mass increases the adverse effects of HIV/AIDS on balance and gait. Phys Ther. 2011;91(7):1063-71.

23. Deeks SG. HIV infection, inflammation, immunosenescence, and aging Annu Rev Med. 2011;62:141-55.

24. Hunt PW. HIV and aging. Curr Opin HIV AIDS. 2014:9(4):302-8.

25. Pathai S, Bajillan H, Landay AL, High KP. Is HIV a model of accelerated or accentuated aging? Journals Gerontol. Ser A Biol Sci Med Sci. 2014;69(7): 833-42. doi:10.1093/gerona/glt168.

26. Erlandson KM, Schrack JA, Jankowski CM, Brown T, Campbell TB. Functional impairment, disability, and frailty in adults aging with HIV-infection. Curr HIV/AIDS Rep. 2014;11:279-90.

27. Deeks SGS, Phillips AN. HIV infection, antiretroviral treatment, ageing, and non-AIDS related morbidity. BMJ. 2009;338(7689):a3172.

28. Pinto Neto LF Da S, Sales MC, Scaramussa ES, da Paz CJC, Morelato RL. Human immunodeficiency virus infection and its association with sarcopenia. Braz J Infect Dis 2016;20(1):99-102.

29. Erlandson KM, Guaraldi G, Falutz J. More than osteoporosis. Curr Opin HIV AIDS. 2016;11(3):343-50

30. Erlandson K, Allshouse A, Jankowski C, MaWhinney S, Kohrt W, Campbell T. Functional impairment is associated with low bone and muscle mass among persons aging with HIV-infection. October. 2013;62(2):209-15.

31. Saccomanno MF, Ammassari A. Bone disease in HIV infection. Clin Cases Miner Bone Metab; 2011;8(1):33-36; PMCID: PMC3230921

32. Stellbrink H-J, Orkin C, Arribas JR, Compston J, Gerstoft J, Van Wijngaerden $E$, et al. Comparison of changes in bone density and turnover with abacavirlamivudine versus tenofovir-emtricitabine in HIV-infected adults: 48-week results from the ASSERT study. Clin Infect Dis. 2010;51(8):963-72.
33. Haskelberg H, Hoy JF, Amin J, Ebeling PR, Emery S, Carr A, et al. Changes in bone turnover and bone loss in HIV-infected patients changing treatment to tenofovir-emtricitabine or abacavir-lamivudine. PLoS One. 2012;7(6): e38377.

34. Compston J. Osteoporosis and fracture risk associated with HIV infection and treatment. Endocrinol Metab Clin N Am. 2014:43:769-80.

35. Scott WB, Oursler KK, Katzel LI, Ryan AS, Russ DW. Central activation, muscle performance, and physical function in men infected with human immunodeficiency virus. Muscle Nerve. 2007;36(3):374-83.

36. Hausdorff JM. Gait dynamics, fractals and falls: finding meaning in the stride-to-stride fluctuations of human walking. Hum Mov Sci. 2007;26(4): 555-89.

37. Newstead AH, Walden JG, Gitter AJ. Gait variables differentiating fallers from nonfallers. J Geriatr Phys Ther. 2007;30(3):93-101.

38. Quach L, Galica AM, Jones RN, Procter-Gray E, Manor B, Hannan MT, et al. The nonlinear relationship between gait speed and falls: the maintenance of balance, independent living, intellect, and zest in the elderly of Boston study. J Am Geriatr Soc. 2011;59(6):1069-73.

39. Toebes MJP, Hoozemans MJM, Furrer R, Dekker J, Van Dieën JH. Local dynamic stability and variability of gait are associated with fall history in elderly subjects. Gait Posture. 2012;36(3):527-31.

40. Moher D, Liberati A, Tetzlaff J, Altman DG, PRISMA group. Preferred reporting items for systematic reviews and meta-analyses: the PRISMA statement. BMJ. 2009;339:b2535.

41. Verghese J, LeValley A, Hall C, Katz M, Ambrose A, Lipton R. Epidemiology of gait disorders in community-residing older adults. J Am Geriatr Soc. 2006; 54(2):255-61.

42. National Heart Lung and Blood Institute. Quality Assessment Tool for Observational Cohort and Cross-Sectional Studies - NHLBI, NIH. National Institutes of Health. 2014. https://www.nhlbi.nih.gov/health-pro/guidelines/ in-develop/cardiovascular-risk-reduction/tools/cohort. Accessed 15 Nov 2015

43. Beans J, Stevenson T, Katzel LI, Sorkin JD, Warner AL, Gottlieb SS, et al. Ambulatory Function in Men with and without HIV Infection: Association with Cardiorespiratory Fitness. J. AIDS Clin. Res. 2013;4(5) doi:10.4172/21556113.59-003

44. Mbada CE, Onayemi O, Ogunmoyole Y, Johnson OE, Akosile CO. Healthrelated quality of life and physical functioning in people living with HIV/ AIDS: a case-control design. Health Qual Life Outcomes. 2013;11(1):106.

45. Cohen HS, Cox C, Springer G, Hoffman HJ, Young MA, Margolick JB, et al. Prevalence of abnormalities in vestibular function and balance among HIVseropositive and HIV-seronegative women and men. PLoS One. 2012;7(5): e38419.

46. Trenkwalder C, Straube A, Paulus W, Krafczyk S, Schielke E, Einhäupl KM Postural imbalance: an early sign in HIV-1 infected patients. Eur Arch Psychiatry Clin Neurosci. 1992;241(5):267-72.

47. Arendt G, Maecker HP, Purrmann J, Hömberg V. Control of posture in patients with neurologically asymptomatic HIV infection and patients with beginning HIV-1-related encephalopathy. Arch Neurol. 1994;51(12):1232-5.

48. Dellepiane M, Medicina MC, Mora R, Salami A. Static and dynamic posturography in patients with asymptomatic HIV-1 infection and AIDS. Acta Otorhinolaryngol. Ital. 2005;25(6):353-358; PMCID: PMC2639898.

49. Simmonds M, Novy D, Sandoval R. The differential influence of pain and fatigue on physical performance and health status in ambulatory patients with human immunodeficiency virus. Clin J Pain. 2005;21(3):200-6.

50. Beckley DJ, Bloem BR, Martin EM, Panzer VP, Remler MP. Postural reflexes in patients with HIV-1 infection. Electroencephalogr Clin Neurophysiol. 1998; 109(5):402-8.

51. Thaler-Kall K, Peters A, Thorand B, Grill E, Autenrieth CS, Horsch A, et al. Description of spatio-temporal gait parameters in elderly people and their association with history of falls : results of the population-based cross-sectional KORA-Age study. BMC Geriatr. 2015;15(32) doi:10.1186/s12877-015-0032-1.52.

52. Callisaya ML, Blizzard L, Martin K, Srikanth VK. Gait initiation time is associated with the risk of multiple falls-a population-based study. Gait Posture. 2016:49:19-24.

53. Sos B. Dual Task Performance And Postural Recovery. Electron. Theses, Treatises Diss. Florida State University;. 2003;Paper 162.

54. Pajala S, Era P, Koskenvuo M, Kaprio J, Törmäkangas T, Rantanen T. Force platform balance measures as predictors of indoor and outdoor falls in community-dwelling women aged 63-76 years. J Gerontol A Biol Sci Med Sci. 2008;63(2):171-8. 
55. Palmieri RM, Ingersoll CD, Stone MB, Krause BA. Center-of-pressure parameters used in the assessment of postural control. J Sport Rehabil. 2002;11(1):51-66.

56. Pasma $J H$, Engelhart $D$, Schouten $A C$, van der Kooij $H$, Maier AB, Meskers CGM. Impaired standing balance: the clinical need for closing the loop. Neuroscience. 2014;267:157-65.

57. Winter D. Human balance and posture control during standing and walking. Gait Posture Elsevier. 1995;3(4):193-214.

58. Lugade V, Kaufman K. Center of Pressure Trajectory during gait: a comparison of four foot positions. Gait Posture NIH Public Access. 2014; 40(1):252.

59. Melzer I, Kurz I, Oddsson LIE. A retrospective analysis of balance control parameters in elderly fallers and non-fallers. Clin. Biomech. (Bristol, Avon). 2010;25(10):984-8.

60. Donath L, Kurz E, Roth R, Zahner L, Faude O. Different ankle muscle coordination patterns and co-activation during quiet stance between young adults and seniors do not change after a bout of high intensity training. BMC Geriatr. BioMed Central; 2015;15:19.

61. Laughton CA, Slavin M, Katdare K, Nolan L, Bean JF, Kerrigan DC, et al. Aging, muscle activity, and balance control: physiologic changes associated with balance impairment. Gait Posture. 2003:18(2):101-8.

62. Heinze B, Swanepoel DW, Hofmeyr LM. Systematic review of vestibular disorders related to human immunodeficiency virus and acquired immunodeficiency syndrome. J Laryngol Otol. 2011;125(9):881-90.

63. Talebi H, Karimi MT, Abtahi SHR, Fereshtenejad N. Static Balance in Patients with Vestibular Impairments: A Preliminary Study. Scientifica (Cairo). 2016; 2016:6539858; doi: 10.1155/2016/6539858.

64. Lockhart TE, Smith JL, Woldstad JC. Effects of aging on the biomechanics of slips and falls. Hum Factors NIH Public Access. 2005;47(4):708-29.

65. Vellas BJ, Wayne SJ, Romero L, Baumgartner RN, Rubenstein LZ, Garry PJ. One-leg balance is an important predictor of injurious falls in older persons. J Am Geriatr Soc. 1997:45(6):735-8.

66. Ageberg $E$, Roberts $D$, Holmström E, Fridén T. Balance in single-limb stance in healthy subjects-reliability of testing procedure and the effect of shortduration sub-maximal cycling. BMC Musculoskelet. Disord. BioMed Central; 2003:4:14.

67. Rinalduzzi S, Trompetto C, Marinelli L, Alibardi A, Missori P, Fattapposta F, et al. Balance dysfunction in Parkinson's disease. Biomed Res Int. 2015:2015: 434683. doi:10.1155/2015/434683.

68. Scholz E, Diener HC, Noth J, Friedemann H, Dichgans J, Bacher M. medium And long latency EMG responses in leg muscles: Parkinson's disease. J Neurol Neurosurg Psychiatry BMJ Group; 1987;50(1):66-70.

69. Studenski S, Duncan PW, Chandler J. Postural responses and effector factors in persons with unexplained falls: results and methodologic issues. J Am Geriatr Soc. 1991;39(3):229-34.

70. Clark S, Iltis PW, Anthony CJ, Toews A. Comparison of older adult performance during the functional-reach and limits-of-stability tests. J Aging Phys Act. 2005;13(3):266-75.

71. Juras G, Słomka K, Fredyk A, Sobota G, Bacik B. Evaluation of the limits of stability (LOS) balance test. J Hum Kinet. 2008;19:39-52.

72. Erlandson K, Kitch D, Kierney C, Sax P, Daar E, Tebas P, et al. Weight and lean body mass change with antiretroviral initiation and impact on bone mineral density: AIDS Clinical Trials Group study A5224s. AIDS. 2013;27(13): 2069-79.

73. Bean JF, Leveille SG, Kiely DK, Bandinelli S, Guralnik JM, Ferrucci L. A comparison of leg power and leg strength within the InCHIANTI study: which influences mobility more? J Gerontol A Biol Sci Med Sci. 2003;58(8):728-33.

74. Russ DW, Scott WB, Oursler KK, King JS. Paradoxical contractile properties in the knee extensors of HIV-infected men treated with antiretroviral therapy. Appl Physiol Nutr Metab. 2010;35(5):713-7.

75. Kusko RL, Banerjee C, Long KK, Darcy A, Otis J, Sebastiani P, et al. Premature expression of a muscle fibrosis axis in chronic HIV infection. Skelet Muscle. 2012;2(1):10

76. Bohannon RW, Magasi S. Identification of dynapenia in older adults through the use of grip strength t-scores. Muscle Nerve NIH Public Access. 2015;51(1):102-5.

77. Schrack JA, Jacobson LP, Althoff KN, Erlandson KM, Jamieson BD, Koletar SL, et al. Effect of HIV-infection and cumulative viral load on age-related decline in grip strength. AIDS. 2016; doi:10.1097/QAD.0000000000001245.

78. Horak FB, Henry SM, Shumway-Cook A. Postural perturbations: new insights for treatment of balance disorders. Phys Ther 1997;77(5):517-533; PMID: 9149762.
79. Mancini M, Horak FB. The relevance of clinical balance assessment tools to differentiate balance deficits. Eur J Phys Rehabil Med. NIH Public Access. 2010;46(2):239-248; PMCID: PMC3033730.

80. Verghese J, Holtzer R, Lipton R, Wang C. Quantitative gait markers and incident fall risk in older adults. J Gerontol A Biol Sci Med Sci. 2009;64(8): 896-901; PMCID: PMC2709543.

81. Fried AV, Cwikel J, Ring H, Galinsky D. ELGAM-extra-laboratory gait assessment method: identification of risk factors for falls among the elderly at home. Int Disabil Stud. 1990;12(4):161-4.

82. Menz HB, Lord SR, Fitzpatrick RC. Acceleration patterns of the head and pelvis when walking are associated with risk of falling in communitydwelling older people. J Gerontol A Biol Sci Med Sci. 2003;58(5):M446-52.

83. Montero-Odasso M, Verghese J, Beauchet O, Hausdorff JM. Gait and Cognition: A Complementary Approach to Understanding Brain Function and the Risk of Falling. J Am Geriatr Soc. 2012;60(11) doi:10.1111/j.15325415.2012.04209.x

84. Ammassari A, Antinori A, Aloisi MS, Trotta MP, Murri R, Bartoli L, et al. Depressive symptoms, neurocognitive impairment, and adherence to highly active antiretroviral therapy among HIV-infected persons. Psychosomatics. 2004;45(5):394-402.

85. Troncoso FT, Conterno L. De O. Prevalence of neurocognitive disorders and depression in a Brazilian HIV population. Rev. Soc. bras. Med. Trop. 2015; 48(4):390-8

86. Holguin A, Banda M, Willen EJ, Malama C, Chiyenu KO, Mudenda VC, et al. HIV-1 effects on neuropsychological performance in a resource-limited country. Zambia AIDS Behav. 2011;15(8):1895-901.

87. Chang L, Wang G-J, Volkow ND, Ernst T, Telang F, Logan J, et al. Decreased brain dopamine transporters are related to cognitive deficits in HIV patients with or without cocaine abuse. Neurolmage. 2008;42(2):869-78.

88. Robertson KR, Parsons TD, Sidtis JJ, Hanlon Inman T, Robertson WT, Hall CD, et al. Timed gait test: normative data for the assessment of the AIDS dementia complex. J Clin Exp Neuropsychol Taylor \& Francis Group. 2006; 28(7):1053-64.

89. Woods SP, Moore DJ, Weber E, Grant I. Cognitive neuropsychology of HIVassociated neurocognitive disorders. Neuropsychol Rev Springer. 2009;19(2): 152-68.

90. ZS DP, Karpman C, Novotny PJ, Benzo RP. Correlations Between Gait Speed, 6-Minute Walk Distance, Physical Activity, and Self-Efficacy in Patients With Severe Chronic Lung Disease. Respir. Care. 2013;58(12):2113-9.

91. Callisaya ML, Blizzard L, McGinley JL, Srikanth VK. Risk sof falls in older people during fast-walking-the TASCOG study. Gait Posture. 2012;36(3):510-5.

92. Moghadam M, Ashayeri H, Salavati M, Sarafzadeh J, Taghipoor KD, Saeedi A, et al. Reliability of center of pressure measures of postural stability in healthy older adults: effects of postural task difficulty and cognitive load. Gait Posture. 2011;33(4):651-5.

93. Peterka RJ, Loughlin PJ. Dynamic Regulation of Sensorimotor Integration in Human Postural Control. J. Neurophysiol. 2004;91(1) doi:10.1152/jn.00516.2003.

94. Cenciarini M, Peterka RJ. Stimulus-dependent changes in the vestibular contribution to human postural control. J Neurophysiol. 2006;95(5):2733-50.

95. Hinkin $\mathrm{CH}$, Castellon SA, Hardy DJ. Dual task performance in HIV-1 infection. J Clin Exp Neuropsychol. 2000;22(1):16-24.

96. Hamacher D, Singh NB, Van Dieën JH, Heller MO, Taylor WR. Kinematic measures for assessing gait stability in elderly individuals: a systematic review. J R Soc Interface. 2011;8(65):1682-98.

97. Mustapa A, Justine M, Mohd Mustafah N, Jamil N, Manaf H. Postural control and gait performance in the diabetic peripheral neuropathy: a systematic review. Biomed Res Int. 2016;2016:1-14.

98. Bridenbaugh SA, Kressig RW. Laboratory review: The role of gfait analysis in seniors' mobility and fall prevention. Gerontol. 2011:57(5):256-64. 